\title{
EVIDENCIAÇÃO DAS AÇÕES DIANTE DAS MUDANÇAS CLIMÁTICAS NOS RELATÓRIOS DAS EMPRESAS PARTICIPANTES DO CARBON DISCLOSURE PROJECT(CDP) BRASIL
}

\author{
Juliano Almeida de Faria 1 \\ José Célio Silveira Andrade 2 \\ Sônia Maria da Silva Gomes 3
}

- Artigo recebido em: 05/03/2019 -- Artigo aceito em: 18/02/2020 -". Segunda versão aceita em: 04/03/2020

\section{RESUMO}

O objetivo deste trabalho foi propor um modelo para a mensuração do nível de evidenciação das ações de enfrentamento às mudanças climáticas a partir de fatores determinantes identificados na literatura (Faria, Andrade e Gomes, 2018B), a saber: prevenção da poluição, volume de emissões de Gases do Efeito Estufa (GEE), gestão de ativos ambientais, prevenção de perdas, estratégica de mudança climática, sistema de gestão ambiental, ramo de atividade, estratégia empresarial, nível de regulação e tamanho da empresa. Com base nisso, foi possível identificar a correlação entre os fatores para a construção do Índice de Evidenciação das Ações diante das Mudanças Climáticas das empresas do CDP, Brasil (IEAMC-CDP). O IEAMC-CDP representa um mecanismo capaz de classificar o nível de evidenciação das ações diante das mudanças climáticas para as empresas do CDP Brasil, sendo composto por fatores que representaram 71,52\% de todas as referências utilizadas nos relatórios anuais publicados no período estudado. O resultado da aplicação do IEAMC-CDP apresenta a empresa ALL (Transportes) como destaque no período, seguida pela B2W (e-commerce) e a CESP (Energia) em terceiro lugar. A evidenciação das ações de enfrentamento às mudanças climáticas por meio dos fatores determinantes mais evidenciados e captados pelo IEAMC-CDP é útil para as empresas na criação de estratégias de divulgação aos stakeholders com vistas à manutenção do contrato social (Teoria

\footnotetext{
1 Doutor em Engenharia Industrial e Mestre em Contabilidade. Professor do Departamento de Ciências Contábeis de Itabaiana-SE - Universidade Federal de Sergipe. Endereço: Av. Vereador Olímpio Grande, s/n, Campus Prof. Alberto Carvalho, Bloco D, Sala 05, ItabaianaSergipe, Brasil, CEP 49506-036. E-mail: profjalmeida@gmail.com https://orcid.org/0000-0002-0143-9790

2 Doutor em Administração. Professor da Escola de Administração da Universidade Federal da Bahia. Endereço: Av. Reitor Miguel Calmon, s/n, $3^{\circ}$ Andar, Sala 21, NPGA, Vale do Canela Salvador-Bahia, Brasil, CEP: 40.1 10-903. E-mail: jcelio.andrade@gmail.com https://orcid.org/0000-0002-6794-8686

3 Doutora em Engenharia de Produção. Professora da Escola de Administração da Universidade Federal da Bahia. Endereço: Av. Reitor Miguel Calmon, s/n, $3^{\circ}$ Andar, Sala 21, NPGA, Vale do Canela, Salvador-Bahia, Brasil, CEP: 40.110-903. E-mail: soniagomes3@gmail.com

https://orcid.org/0000-0003-2024-4419
}

Editora responsável pela aprovação do artigo: $\mathrm{Dr}^{a}$. Bruna Camargos Avelino Editora responsável pela edição do artigo: Drª Bruna Camargos Avelino 
da Legitimidade), em especial para as empresas com menor pontuação na hierarquização de evidenciação apresentada nesta pesquisa. Além disso, sua estrutura permite a aplicação em empresas de diversos portes além das que fazem parte do CDP-Brasil.

Palavras-Chave: Evidenciação. Mudanças Climáticas. Determinantes. Carbon Disclosure Project (CDP).

\title{
DISCLOSURE OF ACTIONS ON CLIMATE CHANGE IN THE REPORTS OF THE COMPANIES PARTICIPATING IN THE CARBON DISCLOSURE PROJECT (CDP) BRAZIL
}

\begin{abstract}
The objective was to propose a model for measuring the level of evidence of actions to cope with climate change based on determinants identified in the literature (Faria, Andrade and Gomes, 2018B), namely: pollution prevention, volume of gas emissions (GHG), environmental asset management, loss prevention, climate change strategy, environmental management system, field of activity, business strategy, regulatory level and company size. Based on this, it was possible to identify the correlation between the factors for building the Index of Evidence of Actions in the face of Climate Change of CDP companies, Brazil (IEAMC-CDP). The IEAMC-CDP represents a mechanism capable of classifying the level of disclosure of actions in the face of climate change for CDP Brasil companies, being composed of factors that represented $71.52 \%$ of all references used in the annual reports published during the period studied. The result of the application of IEAMC-CDP presents the company ALL (Transport) as the highlight in the period, followed by B2W (e-commerce) and CESP (Energy) in third place. Evidence of actions to cope with climate change through the most evident determinant factors captured by the IEAMC-CDP is useful for companies in the creation of strategies for disclosure to stakeholders with a view to maintaining the social contract (Theory of Legitimacy), in particular for the companies with the lowest score in the hierarchy of evidence presented in this research. In addition, its structure allows the application in companies of different sizes besides those that are part of the CDP-Brazil.
\end{abstract}

Keywords: Disclosure. Climate changes. Determinants Carbon Disclosure Project (CDP).

\section{INTRODUÇÃO}

O aquecimento global registrado no planeta nas últimas décadas intensifica a ocorrência de fenômenos naturais e afeta diretamente a produção de alimentos, uso do solo e a qualidade de vida de todos os seres. Na área empresarial os efeitos das mudanças climáticas impactam na capacidade de permanência das empresas no mercado (no curto e no longo prazos) pois provocam alterações, de um lado, na disponibilidade de recursos na cadeia produtiva, e de outro lado, no consumo de produtos e serviços (Hoffman \& 
Evidenciação das Ações Diante das Mudanças Climáticas nos Relatórios das Empresas Participantes do Carbon Disclosure Project (CDP) Brasil

Woody, 2008; Reid \& Toffel, 2009; Sprengel \& Busch, 2011; Linehan, Solicitors, House, \& Place, 2010; Farias, 2017).

Desta forma, os stakeholders desejam conhecer como a empresa os quais têm interesses comerciais é afetada pelas mudanças climáticas, qual é o efeito das mudanças climáticas nas relações com fornecedores e clientes, quais impactos na disponibilidade de matérias primas, no custo do transporte, no preço final dos seus produtos e serviços, entre outras informações (Hoffman \& Woody, 2008; Lee, Park, \& Klassen, 2015; Gallego-Álvarez, Lozano, \& Rodríguez-Rosa, 2018; Zhang \& Liu, 2020). Neste sentido, os stakeholders têm elevado a exigência pelo volume e qualidade das informações das empresas principalmente as gigantes mundiais, as quais demandam maior quantidade de recursos naturais em suas operações.

Em resposta, estas empresas também têm elevado os investimentos em ações de mitigação e adaptação às mudanças climáticas bem como utilizado instrumentos de comunicação capazes de responder às demandas por transparência empresarial (Engau \& Hoffman, 2011; Sullivan \& Gouldson, 2012; Birnik, 2013). Parte importante neste processo, a evidenciação consiste na divulgação das informações pela empresa, tanto de ordem econômica e financeira quanto de ordem não-financeira, com o objetivo de atender, além da obrigação legal, as necessidades dos diversos tipos de usuários da informação contábil divulgada (Hendriksen \& Van Breda, 1999; Pires \& Silveira, 2008). A evidenciação de informações contábeis comunica informações sobre empresas e vem sendo utilizada com um instrumento de atendimento à esta expectativa dos stakeholders no âmbito contábil no que se refere às informações minimamente obrigatórias, incluindo o relatório da anual da administração no qual consta as demonstrações contábeis (Kos, 2014).

Além disso também são utilizados no processo de comunicação com os stakeholders outros relatórios anuais voluntários os quais recebem nomes variados como relatórios para sustentabilidade, relatório do desenvolvimento sustentável, balanço ambiental, entre outros (Fernandes, 2012; Garcia, Cintra, de Souza Ribeiro, \& Dibbern, 2015). Trabalhos como os de Farias (2008), Murcia, Rover, Lima, Fávero e Lima (2008), Rover, Tomazzia, Murcia e Borba (2012), Fernandes (2012), Antal e Van Den Bergh (2013), Burgwal e Vieira (2014), Silva, Lima, Freitas e Lagioia (2015), Braam, Weerd, Hauck e Huijbregts (2016) e Gallego-Álvarez, Lozano e Rodríguez-Rosa (2018), têm identificado maior volume de evidenciação, frequentemente medida essencialmente em função da quantidade de termos relacionados ao tema nos relatórios anuais obrigatórios e voluntários. Sendo assim, o objetivo geral deste trabalho foi propor um modelo para mensuração do nível de evidenciação das ações de enfrentamento as mudanças climáticas a partir de fatores determinantes identificados na literatura.

Pode-se afirmar que os stakeholders têm interesse em empresas com boa reputação, sobretudo pelo fato de que uma boa reputação está relacionada positivamente com a criação de valor para a entidade (Lopes, 2017). Incremento na transparência empresarial auxilia no processo de construção de legítima reputação, sendo de interesse dos stakeholders, uma vez que estes desejam conhecer quais ações têm sido executadas diante da necessidade de mitigar os efeitos ou adaptar-se às mudanças climáticas (Engau \& Hoffman, 201 1; Sullivan \& Gouldson, 2012; Birnik, 2013). 
Verifica-se que a aplicação da política de evidenciação por meio de relatórios anuais possibilita, além da formulação de opiniões dos stakeholders acerca das empresas, auxilia à legitimação da organização e suas expectativas de se sustentar no mercado (Deegan, 2002; Dias Filho, 2012; Begum \& Pereira, 2015). O esforço desempenhado pela entidade em se legitimar perante a sociedade se traduz na prática de medidas sustentáveis e na evidenciação de informações acerca dessas práticas (Deegan, 2002; Eugénio, 2010, Deegan, 2017).

Entende-se, portanto, que os esforços validadores da qualidade da evidenciação são desenvolvidos estrategicamente pelas organizações (Begum \& Pereira, 2015) com o objetivo de continuar extraindo recursos do meio ambiente necessários para a efetivação da sua atividade revelando aspectos importantes de sua legitimação na sociedade (Eugénio, 2010; Dias Filho, 2012). Assiste-se assim a um aumento do volume de investigação de modo a conhecer as práticas de divulgação e dos seus fatores determinantes (Silva, Lima, Freitas, \& Lagioia, 2015; Braam, Weerd, Hauck, \& Huijbregts, 2016). A maior parte da literatura se centra no relato ambiental voluntário (Amran, Periasamy \& Zulkafli, 2014) no entanto são poucos os que se debruçam especificamente sobre os fatores determinantes da divulgação de informação relacionada com ações diante das mudanças climáticas. Fatores determinantes são itens cuja existência na empresa impacta diretamente nas ações da empresa diante das mudanças climáticas, portanto, mantêm relação com as mudanças climáticas. Esta relação é medida nesta pesquisa a partir da menção dos mesmos na evidenciação dos relatórios anuais (obrigatórios e voluntários).

Para melhor contribuir no processo de evidenciação das ações diante das mudanças climáticas pesquisas como as de Rover, Tomazzia, Murcia, \& Borba (2012), Ribeiro, Guzmán, da Silva Monteiro, \& Guzmán, (2012) Antal \& Van Den Bergh (2013), Burgwal \& Vieira (2014) e Silva, Lima, Freitas e Lagioia (2015) têm demonstrado os principais fatores determinantes da evidenciação ambiental tais como tamanho da empresa, ramo de atividade, independência dos diretores e desempenho ambiental. Entretanto, nenhuma destas pesquisas apoia sua análise exclusivamente nas empresas do CDP Brasil ou do CDP em outros países. O CDP tem reunido interesses de investidores em todo o mundo os quais estão atentos às informações apresentadas pelo órgão originadas das empresas em escala mundial que respondem ao questionário do CDP, principalmente quanto ao volume de emissão de GEE. Zhang e Liu (2020) indicam que a divulgação envolvendo emissão de GEE e mudanças climáticas têm aumentado nos últimos anos, mas o conteúdo e a qualidade da divulgação ainda precisam ser aprimorados.

Esta pesquisa é a terceira fase de um amplo estudo associado à identificação dos fatores determinantes da evidenciação das ações diante das mudanças climáticas. O primeiro estudo apresentado em Faria, Andrade e Gomes (2018A) identificou 32 fatores com base na opinião de 34 gestores das empresas a participantes do CDP-Brasil e 32 especialistas (professores, pesquisadores e coordenadores de grupos de pesquisa). $O$ segundo estudo (Faria, Andrade \& Gomes, 2018B), identificou os 32 fatores em 463 relatórios anuais das empresas participantes do CDP Brasil analisando-os por meio do software de análise qualitativa $\mathrm{Nvivo} \circledast$ versão 11 . Os resultados apresentaram os principais fatores determinantes com base no volume de evidenciação nos relatórios 
Evidenciação das Ações Diante das Mudanças Climáticas nos Relatórios das Empresas Participantes do Carbon Disclosure Project (CDP) Brasil

analisados medidos pelo percentual de cobertura apresentado como resultado da análise qualitativa. Nesta etapa, os dados foram correlacionados e ponderados de modo a propor um índice (IEAMC-CDP) capaz de congregar métricas atribuídas pelos especialistas e pelos resultados reais apresentados nos relatórios anuais. Além disso, o mesmo foi reaplicado na amostra geral para construção de um ranking avaliativo das empresas do CDP Brasil que mais evidenciaram ações diante das mudanças climáticas.

De acordo com os pressupostos da Teoria da Legitimidade é possível afirmar que a aferição do nível de evidenciação contribui para identificar as empresas melhores pontuadas, ou seja, aquelas que mais têm se esforçado para levar informação à sociedade em que opera. Ainda segundo a Teoria, esta ação contribui para a legitimação no mercado por meio da manutenção do contrato social. Portanto, o IEAMC-CDP é um instrumento capaz de contribuir no processo de legitimação das empresas no Brasil, uma vez que foi construído com base na opinião de participantes do mercado e nos relatórios já apresentados à sociedade.

Diante do exposto nota-se que processo de evidenciação é complexo pois envolve a identificação de informações que possam satisfazer os interesses dos stakeholders, inclusive pelo fato da relação positiva entre evidenciação e desempenho (Kos, 2014; Guia, 2017, Zhang \& Liu, 2020). Lee, Park e Klassen (2015) indicam que investidores tendem a perceber a divulgação de GEE como uma má notícia e, portanto, estão preocupados com os custos potenciais que as empresas podem vir a dispor para enfrentar o aquecimento global. Por outro lado, e ainda segundo os autores, uma empresa pode mitigar esta situação por meio do aumento do volume de divulgação de GEE por meio de diversos meios de comunicação e não apenas anualmente via questionário do CDP.

Neste sentido a Teoria da Legitimidade prediz que as empresas buscam evidenciar em seus relatórios anuais as informações que serão mais úteis para legitimar-se frente a eles, partindo do pressuposto que tais informações atendem aos interesses socialmente construídos pelos stakeholders, (Deegan, 2002; Dias Filho, 2012; Begum \& Pereira, 2015; Barakat, Freitas, Boaventura, \& MacLennan, 2016), hoje cada vez mais interessados nas ações diante das mudanças climáticas. Parte-se do pressuposto que as empresas que melhor evidenciam proporcionam mais transparência aos stakeholders e assim tornam-se mais legítimas garantindo continuidade operacional por meio de maior valorização no mercado.

Sendo assim, considerando a crescente necessidade dos stakeholders de informação acerca das ações que as empresas veem tomando diante das mudanças climáticas, da lacuna existente quanto ao aprofundamento de estudo sobre mensuração e evidenciação dessas ações das empresas participantes do CDP, e a necessidade das empresas (sobretudo as grandes empresas participantes do CDP) de manterem a legitimidade no mercado por meio, dentre outros aspectos, da evidenciação de informações que possam atender ao interesse dos stakeholders, este trabalho apresenta o seguinte problema de pesquisa: De que maneira é possível mensurar a evidenciação das ações diante das mudanças climáticas nos relatórios anuais das empresas participantes do CDP Brasil? O objetivo do trabalho é propor o IEAMC-CDP para mensuração do nível de evidenciação das ações diante das mudanças climáticas para as empresas do CDP Brasil a partir da avaliação atribuída pelos especialistas, 
gestores e pela avaliação da menção nos relatórios anuais.

Os stakeholders têm valorizado as empresas que mantém política de comunicação de informações ambientais, entretanto, ainda é preciso ampliar o volume de informações e a qualidade de modo a viabilizar a comparabilidade entre as empresas (Cotter \& Najah, 2012; Sullivan \& Gouldson, 2012). Os resultados desta pesquisa podem contribuir para que os gestores (participantes da amostra ou não) possam avaliar a estratégia de evidenciação no que se refere à divulgação de conteúdo que seja útil ao stakeholders, ampliando o volume de evidenciação das informações acerca das ações diante das mudanças climáticas.

Zhang e Liu (2020) confirmam que no contexto da abordagem das mudanças climáticas globais e da redução de emissões de carbono, a divulgação corporativa de informações sobre emissão de GEE tornou-se uma medida importante para alcançar a redução de emissões de GEE em todo o mundo e um ponto de acesso à pesquisa investigado de perto pela academia. Assim, esta pesquisa poderá ainda contribuir para que as empresas desenvolvam ações de mitigação/adaptação diante das mudanças climáticas causadas pela emissão de GEE de acordo com os determinantes identificados de modo que possam dispor de informações para evidenciação e, consequentemente, contribuir para a redução do aquecimento global.

De modo adicional, considera-se que ações voluntárias, em resposta às mudanças climáticas, podem estar integradas aos princípios empresariais e, em alguns casos, na cadeia produtiva como um modelo de negócio transparente (Ihlen \& Roper, 2014). Uma destas práticas voluntárias é o atendimento de informações solicitadas anvalmente pelo Carbon Disclosure Project (CDP), órgão internacional sediado no Reino Unido que reúne investidores mundiais e busca aumentar a transparência das empresas no que se refere à emissão e tratamento de GEE. Considerando a representatividade mundial do CDP, esta pesquisa trabalha com empresas que vêm respondendo ao seu questionário anual, portanto, estão na vanguarda do processo de evidenciação voluntária das medidas de mitigação e ou adaptação de mudanças climáticas.

Diversas pesquisas vem estudando o processo de evidenciação ambiental, como Antal e Van Den Bergh (2013), Amran, Periasamy e Zulkafli (2014), Doná (2015) e Braam, Weerd, Hauck e Huijbregts (2016), incluindo a evidenciação das ações diante das mudanças climáticas por meio dos relatórios anuais. De modo adicional, a pesquisa de Akbaş e Canikli (2018), usando modelos de regressão logística com uma amostra de 84 empresas turcas listadas no CDP descobriram que o tamanho da empresa, a propriedade institucional e o valor de mercado estão positivamente relacionados à sensibilidade das empresas incluídas na amostra quanto à transparência na evidenciação de produção de gases de efeito estufa (GEE).

O trabalho de Faria, Andrade e Gomes (2018A) apresenta os fatores determinantes destas práticas concretizadas por meio dos dados e índices publicados nos relatórios anuais em empresas participantes do CDP Brasil. Estas ações são capazes de promover a mitigação e/ou adaptação diante das mudanças climáticas e assim conduzir as corporações à sobrevivência, neste cenário posto ao mercado em nível mundial. Cabe ressaltar ainda que as empresas brasileiras participantes do CDP são, sobretudo, grandes empresas 
Evidenciação das Ações Diante das Mudanças Climáticas nos Relatórios das Empresas Participantes do Carbon Disclosure Project (CDP) Brasil

nacionais e multinacionais, com respectivo potencial de impacto das suas operações em nível local e global (latridis, 2013). Por isso, contribuir com subsídios para avaliação da legitimidade destas empresas representa impactar indiretamente em operações de escala mundial, com efeitos num horizonte de longo prazo no que tange a geração de ações de enfrentamento das mudanças climáticas, afinal os stakeholders têm valorizado as empresas que mantém política de comunicação de informações ambientais (Cotter \& Najah, 2012; Sullivan \& Gouldson, 2012).

O IEAMC construído a partir dos fatores determinantes da evidenciação das ações diante das mudanças climáticas identificados por Faria, Andrade e Gomes (2018B) assume posição no estudo da evidenciação pois podem auxiliar a tomada de decisão sobre as ações da empresa, demonstrando aos stakeholders, intrinsecamente, sua estratégia diante das mudanças climáticas. Ao utilizar outras fontes voluntárias de evidenciação é possível preencher a lacuna existente quanto ao aprofundamento de estudo sobre evidenciação das ações diante das mudanças climáticas em empresas brasileiras para além dos itens financeiros divulgados nos relatórios. O ineditismo da combinação dos métodos aplicados de acordo com a proposta desta pesquisa contribui para encontrar um índice construído a partir de pesquisa qualitativa com pressupostos emanados por gestores e especialistas no Brasil, além da coleta empírica nos relatórios das empresas em análise (Faria, Andrade, \& Gomes, 2018B).

A sociedade precisa de mais informação para viabilizar a legitimação das práticas dessas empresas permitindo sua continuidade na sociedade (Deegan, 2002; Barakat, Freitas, Boaventura, \& MacLennan, 2016). De acordo com Eugénio, Lourenço e Morais (2013), existem falhas no processo de legitimação quando as expectativas sociais de comportamento da empresa diferem das percepções sociais de seu comportamento. Nestas circunstâncias a sociedade poderia revogar o contrato social da organização para continuar suas operações representando um contraponto à estratégia definida pelos gestores (Deegan, 2002; Eugénio, Lourenço, \& Morais, 2013, Deegan 2017).

Nesta direção, a divulgação de informações operacionais e financeiras por meio dos relatórios anuais constitui instrumento que contribui no processo de legitimação da empresa diante da sociedade. Entretanto, a divulgação ambiental no Brasil ainda é uma ação voluntária das empresas, que por sua vez, optam por investir recursos nas práticas ambientais, na confecção e divulgação de relatórios anuais dessa natureza para atendimento dessa demanda social (Macêdo, de Moura, Gollo, \& Klann, 2014), visando a manutenção da legitimidade (Dias Filho, 2012; Mousa \& Hassan, 2015).

O CDP já havia criado em 2012 um mecanismo de pontuação que afere a transparência das empresas que respondem aos seus questionários anuais (CDP, 2014). Entretanto, o índice do CDP limita-se aos dados provenientes dos questionários do próprio CDP, portanto, não contempla os demais relatórios anuais (obrigatórios e voluntários) emitidos pelas empresas. Diante disso, a contribuição do trabalho por meio da disponibilização do IEAMC-CDP amplia a construção/manutenção do processo de legitimação uma vez que o índice avalia a empresa por meio dos relatórios de divulgação compulsória (obrigatórios pela sociedade em que atuam) e voluntária. Além disso, o IEAMC-CDP considera a opinião de especialistas e gestores apontando os fatores determinantes mais significativos para a evidenciação das ações diante das mudanças climáticas. 


\section{REFERENCIAL TEÓRICO}

\subsection{Teoria da Legitimidade}

No cenário mundial atual evidências mostram que a sociedade passou a cobrar uma nova postura empresarial baseada na ideia de buscar crescimento econômico em consonância com a responsabilidade ambiental. Neste sentido e com gestores visando a longevidade da empresa no mercado, a incorporação de ações socioambientais em suas operações e nas práticas de negócios é, entre outros aspectos, uma medida que tem sido valorizada pela sociedade (Eugénio, Lourenço, \& Morais, 2013; Silva, Rodrigues, \& Lagioia, 2019).

Parte importante neste processo, os relatórios anuais (obrigatórios e voluntários) são o principal mecanismo de comprovação e divulgação de que a empresa desenvolve ações socioambientais, inclusive aquelas capazes de contribuir para a redução da geração de GEE, principal responsável pelas mudanças climáticas. Além disso, os resultados da pesquisa de Dwyer, Lamond, Prado-Lorenzo, Rodríguez-Domínguez, Gallego-Álvarez e García-Sánchez (2009) sugerem uma tendência para as empresas utilizarem informações sobre emissões de GEE como um mecanismo que permite legitimar-se com os grupos capazes de trazer benefícios para eles.

Com o advento da valorização de temas sustentáveis o comportamento empresarial vem sendo submetido a novos desafios de modo a atender às expectativas do mercado quanto a uma postura de gestão sustentável nos negócios. Segundo Eugénio, Lourenço e Morais (2013), é importante que as empresas comuniquem como integrar conceitos de sustentabilidade em suas decisões e informem aos stakeholders sobre seus projetos e ações de sustentabilidade. Isso é importante pois uma vez que suas práticas estejam de acordo com as expectativas dos stakeholders a empresa tende a conquistar a legitimidade na sociedade. Neste contexto, Suchman (1995) afirma que legitimidade é uma percepção generalizada ou suposição de que as ações de uma organização são desejáveis, próprias ou apropriadas dentro de algum sistema social de normas, valores, crenças e definições.

A Teoria da Legitimidade possui um enfoque sociológico manifestado por meio da preocupação das empresas em referendar sua atuação na sociedade por meio do cumprimento e respeito aos princípios relativos ao meio ambiente, cidadania, costumes e do ordenamento jurídico de seu entorno. Isso ocorre por meio da execução e evidenciação de suas atividades econômicas, utilização de recursos humanos, materiais e do impacto ambiental, visando o fortalecimento de sua imagem institucional e redução das pressões sociais (Conceição, Dourado, \& Silva, 2012).

Fortemente baseada neste conceito, segundo Mousa e Hassan (2015, p. 48) os objetivos da Teoria da Legitimidade podem ser identificados a partir da descrição das relações entre uma empresa e a sociedade na qual desenvolve suas operações, a saber: "explicar as motivações das empresas para divulgações sociais e ambientais; apresentar como as empresas podem usar estratégias de legitimidade; e determinar os impactos das divulgações sociais e ambientais sobre o público e a sociedade". 
Evidenciação das Ações Diante das Mudanças Climáticas nos Relatórios das Empresas Participantes do Carbon Disclosure Project (CDP) Brasil

A Teoria da Legitimidade pode ajudar a prever as respostas da administração a eventos ou crises particulares (Mousa \& Hassan, 2015). Por outro lado, Barakat, Freitas, Boaventura, \& MacLennan, (2016) apresentam, com base em evidências empíricas, a evolução do conceito na Teoria dos Stakeholders com base numa perspectiva avaliativa do papel do stakeholder diante da organização, sobretudo referente ao poder do stakeholder em influenciar a organização, a legitimidade da organização com relação ao stakeholder e a urgência das reivindicações do stakeholder.

Barakat, Freitas, Boaventura, \& MacLennan, (2016) ainda apontam a necessidade de continuidade na discussão do tema assim como demonstram recente aumento do volume de pesquisas neste arcabouço, com destaque para o conceito de legitimidade de Suchman (1995) e com a maioria (46\%) dos artigos pesquisados utilizando a abordagem de legitimidade a partir da Teoria dos Stakeholders. Este é o arcabouço teórico utilizado neste trabalho pois busca-se descobrir os fatores determinantes da evidenciação das ações diante das mudanças climáticas tendo como premissa o interesse dos stakeholders por este tema.

Os stakeholders buscam informações capazes de possibilitar a avaliação e julgamento dos meios utilizados pelas empresas para o alcance de seus objetivos empresariais e a forma com a qual se utilizam dos recursos postos à sua disposição através da concessão social, bem como do respeito aos princípios éticos e legais estabelecidos pela sociedade (Conceição, Dourado, \& Silva, 2012).

De modo adicional, a Teoria da Legitimidade ressalta que a divulgação de informação voluntária busca provar o posicionamento da empresa em ser ambientalmente responsável e que desenvolve a sua atividade de forma a cumprir com os valores impostos pela sociedade para divulgação de informação. A Teoria da Legitimidade pode servir como base para explicar os motivos pelos quais algumas empresas divulgaram mais informações ambientais do que outras, assim como a qualidade das informações divulgadas. Uma explicação para a alta divulgação ambiental pode ser a intenção de sinalizar para o mercado o seu bom desempenho ambiental e aumentar seu valor para os acionistas (Silva, Rodrigues, \& Laioia, 2019).

Com isso a empresa procura não só legitimar-se com a sociedade no que tange aspectos ambientais, como também, com outras empresas com as quais interage de modo a destacar-se no mercado entre as concorrentes. "As organizações que são tidas como legítimas, tendem a ter maior possibilidade de sobrevivência e maior capacidade de angariar recursos do que aquelas não legítimas" (Rossoni, 2016, p. 122). As empresas legítimas gozam de mais credibilidade no mercado, levando a atribuição de maior confiança por parte dos stakeholders quanto as ações daquela empresa.

Enquanto instituições sociais, as empresas operam através de mandado expresso por meio de contrato social e, para sua manutenção ou permanência, necessitam oferecer produtos, mercadorias ou serviços voltados ao atendimento às necessidades da coletividade, resguardando os limites estabelecidos para essa atuação (Conceição, Dourado, \& Silva, 2012; Rossoni, 2016). Contrato social, segundo a Teoria da Legitimidade, é um acordo (formal ou não-formal) entre a sociedade (fornecendo recursos naturais, infraestrutura, mão de obra e expectativas) e a empresa que nela opera (devolvendo preservação dos 
recursos naturais, pagamento de benefícios sociais, geração de produtos e serviços). Assim, se a continuidade de uma organização depende da capacidade de atuar em sintonia com as expectativas da sociedade, é de esperar que ela se esforce para que as suas atividades sejam aceitas e percebidas como legítimas (Deegan, 2002; Dias Filho, 2012).

Este processo de aceitação passa necessariamente pela evidenciação das ações realizadas (e seus resultados) nos relatórios direcionados aos stakeholders, sendo estas importantes fontes de informação e avaliação dos esforços de legitimação das empresas (Dias Filho, 2012). A Figura 1, demonstra o fluxo do contrato social previsto pela Teoria da Legitimidade.

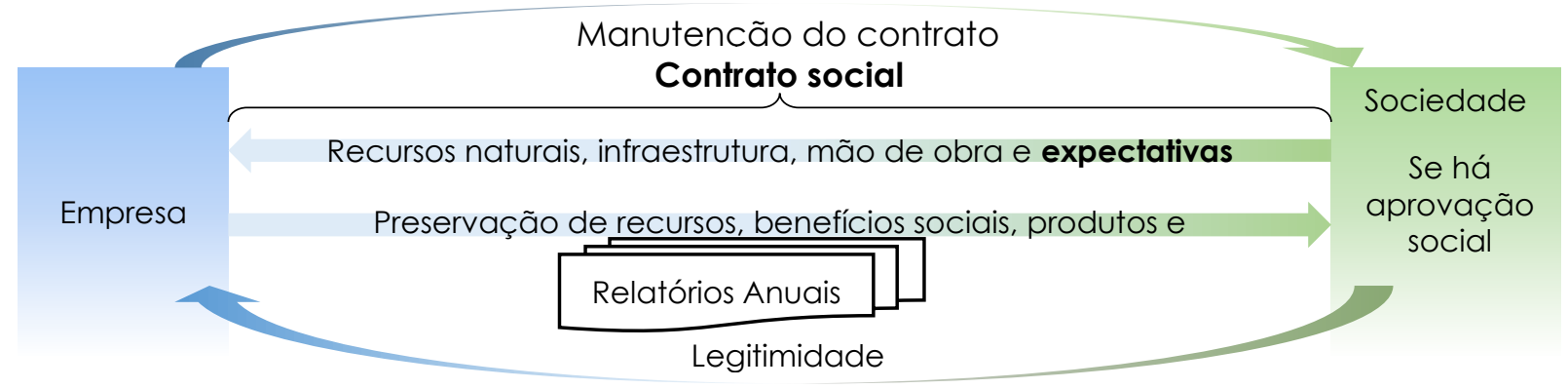

Figura 1 - Fluxo do Contrato Social previsto pela Teoria da Legitimidade Fonte: Adaptado de Mousa e Hassan (2015).

Este conceito tem sido apontado frequentemente nas pesquisas no Brasil (Barakat, Freitas, Boaventura, \& MacLennan, 2016) pressupondo o Contrato Social existente entre a sociedade e as empresas, as quais têm a obrigação moral de agir de forma socialmente responsável com o ambiente em que atuam (O'Donovan, 2002; Dias Filho, 2012; Eugénio, 2010; Machado \& Ott, 2015). Existe uma lacuna de legitimidade quando há incongruência entre as ações de uma corporação e as percepções da sociedade do que essas ações deveriam ser (O'Donovan, 2002). Neste caso, a sociedade poderá romper esse contrato e a sobrevivência da empresa na sociedade estará ameaçada uma vez que as pressões sociais pelo rompimento do contrato social serão ampliadas (Deegan, 2002; Eugénio, 2010; Correa, Gonçalves, \& Moraes, 2015; Rossoni, 2016).

As estratégias de sustentabilidade, que incluem o processo de divulgação de informação ambiental, inclusive acerca das mudanças climáticas, são encaradas como uma das principais formas das empresas apresentarem uma imagem socialmente responsável visando legitimar os seus comportamentos junto dos seus stakeholders (Eugénio, Lourenço, \& Morais, 2013). Segundo Barros e Monteiro (2012), fenômeno da evidenciação por meio dos relatórios anuais é sinônimo de resposta às mudanças estruturais e de interação mais transparente com os seus stakeholders.

Entretanto, este processo tem gerado algumas tensões na construção de estratégias na atualidade, uma vez que se faz necessário conciliar interesses eventualmente conflitantes entre investir em mudanças estruturais em busca da redução de GEE, produzir resultados financeiros que atendam aos interesses dos investidores e ainda assim manter-se legitimidade no mercado. Neste cenário reside uma potencial dissociação com o nível organizacional das empresas frente 
Evidenciação das Ações Diante das Mudanças Climáticas nos Relatórios das Empresas Participantes do Carbon Disclosure Project (CDP) Brasil

à estratégia de sustentabilidade e o trabalho com a Teoria da Legitimidade pode contribuir para atenuar possíveis dissociações (Hengst, Jarzabkowski, Hoegl, \& Muethel, 2020).

A princípio, elas se legitimam na medida em que conseguem alinhar suas práticas com as normas e padrões de comportamento defendidos no ambiente em que operam (Deegan, 2002; Dias Filho, 2012). Eugénio, Lourenço e Morais (2013) realizaram um estudo de caso numa das maiores empresas de cimento portuguesa, área de produção que se destaca pelo alto impacto ambiental associado à sua atividade produtiva. Por meio dos relatórios de sustentabilidade e de entrevistas semiestruturadas as autoras identificaram diversas estratégias de manutenção da legitimidade utilizada pela empresa em momentos de crise, sobretudo no que tange impactos ambientais. As autoras concluíram com a sustentação do argumento de que estratégias de sustentabilidade continuam sendo uma poderosa ferramenta positiva de legitimidade, sobretudo para empresas que causam impactos ambientais significativos.

O resultado dessa capacidade de adesão a valores pertinentes ao ambiente em que operam, sugere analisar o empenho de tais empresas em serem percebidas como organizações que atuam em conformidade com o esperado pelos agentes com os quais se relacionam, os stakeholders. Pereira, Bruni e Dias Filho (2010) justificam que uma das razões para o crescimento na divulgação de informações de caráter ambiental está na busca de legitimidade das organizações junto à sociedade de modo a amenizar o impacto da sua atividade no meio ambiente e na imagem da empresa para a sociedade. A manutenção da imagem da empresa como socialmente responsável, a entidade precisa divulgar essas informações por meio dos relatórios ambientais anvais (Machado \& Ott, 2015).

Consequentemente a evidenciação por meio dos relatórios anuais pode auxiliar as empresas a manter a imagem necessária quanto a manutenção do contrato social para a sociedade (Eugénio, 2010; Machado \& Ott, 2015). Portanto, a identificação dos fatores determinantes a partir dos relatórios anvais é uma forma de contribuição para apontar quais são os mecanismos de sustentação do contrato social referente à evidenciação das ações diante das mudanças climáticas no Brasil. Os fatores determinantes também demonstram como ocorre o processo de legitimação por meio das práticas de evidenciação das ações das empresas diante das mudanças climáticas. Com isso, eles mostram o perfil de evidenciação das empresas e, por sua vez, pode mostrar um caminho valorizado pelos stakeholders das práticas empresariais.

Por meio da identificação dos fatores determinantes mais evidenciados as empresas podem ampliar ou direcionar seu volume de informações pois estes são mais reconhecidos pelos stakeholders e, por sua vez, buscarão informações sobre as mudanças climáticas em seus relatórios anuais. Sendo assim, faz-se necessário confirmar quais dos 32 fatores determinantes identificados na literatura têm se destacado nas evidenciações por meio de uma hierarquização. Dessa forma pode-se ajudar as empresas a melhor atender os interesses dos stakeholders uma vez que as organizações estão dispostas a ampliar o disclosure em sustentabilidade empresarial quando percebem que podem obter benefícios capazes de facilitar o alcance de suas metas organizacionais e econômicas (Conceição, Dourado, \& Silva, 2012). 
Sendo assim, busca-se atingir o objetivo geral desta pesquisa por meio da proposição um modelo para mensuração do nível de evidenciação das ações de enfrentamento as mudanças climáticas a partir de fatores determinantes identificados em relatórios (obrigatório e voluntário) e da opinião de especialistas e gestores, sendo realizada uma discussão fundamentada na Teoria da Legitimidade.

\section{PROCEDIMENTOS METODOLÓGICOS}

A estratégia metodológica desta pesquisa foi delineada com vista a atingir o objetivo geral a partir dos respectivos cumprimentos dos objetivos específicos. O fluxo da aplicação do método foi exclusivo a este trabalho e atendeu ao objetivo geral da pesquisa uma vez que permitiu o uso dos fatores determinantes identificados por Faria, Andrade e Gomes (2018B) para a construção do IEAMCCDP. Foram utilizados os relatórios anuais oficiais disponíveis nos sites das empresas para comunicação de informações aos stakeholders das 48 empresas participantes do CDP nos anos base de 2014 a 2016, a saber: Relatório da Administração (RA), Demonstrações Financeiras Padronizadas (DFP), Relatórios de Sustentabilidade (RS) e Formulários de Referência (FR). Cabe ressaltar que algumas empresas apresentaram O RS inserido no RA, assim como outras apresentaram as DFP também inseridas no RA. Nestes casos a contagem do relatório foi unificada pois encontram-se num único arquivo contendo os dois relatórios. Entretanto a análise foi individualizada.

O Nvivo® é sistema de análise documental que disponibiliza ferramentas de análise textual proveniente de relatórios, transcrições de áudio, imagens e outros dispositivos de comunicação. Este sistema viabilizou a organização e análise dos dados necessários para desenvolver a pesquisa de Faria, Andrade e Gomes (2018B) no qual apresentou o modelo de construção capaz de identificar os fatores determinantes utilizados nessa pesquisa para a construção do IEAMCCDP.

Esta pesquisa consiste em propor o IEAMC para mensuração do nível de evidenciação das ações diante das mudanças climáticas para as empresas do CDP Brasil, a partir da avaliação atribuída pelos especialistas, gestores e pela avaliação da menção nos relatórios anuais. A construção desta etapa da pesquisa leva em consideração os resultados atingidos por Faria, Andrade e Gomes (2018B) como informações extraídas do banco de dados disponível no software Nvivoß, a partir da qual disponibiliza-se 32 Nós (fatores determinantes) correlacionados com os relatórios anuais das 48 empresas participantes da pesquisa.

Em sua estrutura, o Nvivo® disponibiliza uma ferramenta de codificação de dados denominada Caso. Os casos são recipientes de codificação que representam unidades de observação, por exemplo, pessoas, lugares, organizações ou artefatos (Guia Nvivo, 2017). Os casos auxiliam na congregação de informações presentes nos Nós, já armazenados em função do desenvolvimento natural da pesquisa (leitura dos relatórios anuais e codificação dos Nós). Neste caso, esta ferramenta foi fundamental para agrupar informações presentes nos relatórios anuais as quais permitiam a codificação em dois ou mais nós simultaneamente. Cabe ressaltar que a codificação individual fica 
Evidenciação das Ações Diante das Mudanças Climáticas nos Relatórios das Empresas Participantes do Carbon Disclosure Project (CDP) Brasil

preservada. O software permite a criação de um novo processo de codificação condicionado aos Nós, denominado Caso, permitindo perceber relações entre os Nós, bem como menções nos relatórios que direcionam para a similaridade contextual do assunto aos mesmos fatores determinantes.

Nesta pesquisa os Casos foram criados pelos autores na medida em que os Nós eram identificados, ou seja, no mesmo momento em que um determinado trecho foi identificado como associado a dois Nós, um Caso (associado àqueles dois Nós) também foi criado paralelamente com respectiva codificação e armazenamento em seu recipiente daqueles dados. Os Casos apresentaram, portanto, um volume paralelo aos Nós (e associado a eles) de trechos que correlacionam os Nós, permitindo assim uma análise mais compacta dentre o volume de 32 Nós (fatores determinantes) utilizados na pesquisa. Vale lembrar que nem sempre a codificação de um Nó condizia a obrigatoriedade da criação de um Caso, ocorrendo este último apenas quando da identificação de correlação do texto para dois ou mais Nós.

Além disso, o Nvivo® viabilizou o cálculo do coeficiente de correlação de Pearson, que mede o relacionamento entre variáveis (covariância) a partir da padronização do valor identificado nos dados amostrais. Segundo Field (2009), um coeficiente positivo igual a 1 (um) indica que as variáveis são perfeitamente correlacionadas de forma positiva, assim, enquanto uma variável aumenta na amostra, a outra correlacionada a ela aumenta proporcionalmente. Um coeficiente igual a -1 (menos um) indica que a correlação é negativa perfeita, ou seja, inversamente proporcional, assim como o índice 0 (zero) indica ausência de relacionamento linear entre as variáveis estudadas. O coeficiente de correlação de Pearson de cada Caso foi calculado de modo a confirmar o nível de correlação entre os Nós que compõem o Caso, inicialmente identificado pelo pesquisador a partir da análise documental.

Aqueles Casos com maiores coeficientes confirmam estatisticamente maior correlação entre as variáveis (Nós) e permitem assim a agregação dos seus resultados uma vez que indicam referência ao mesmo assunto, mesmo que utilizando dois ou mais Nós. Com isso, foi possível avaliar a qualidade correlacional dos Casos criados e selecionar aqueles com maior coeficiente de correlação para agregação, ou seja, permitindo a compactação do volume de fatores determinantes analisados tomando como referência sua respectiva correlação.

Os Casos calculados pelo Nvivo ${ }^{\circledR}$ apresentam fatores determinantes cujos respectivos percentuais de cobertura apontam para o mesmo sentido textual, medido na codificação e validado pelo coeficiente de Pearson. Entretanto, para fins de construção do modelo, faz-se necessário inserir o peso dos respectivos fatores identificados, de modo a manter maior capacidade preditiva de cada Caso, assim como vem sendo feito no decorrer deste trabalho. Assim, não apenas o percentual de cobertura foi utilizado, mas também o peso auferido a partir da opinião de especialistas e gestores (no questionário e na entrevista). Para identificação de único peso para o Caso, foi calculada a média e o desvio padrão dos pesos individuais

O Índice de Evidenciação das Ações diante das Mudanças Climáticas (IEAMC-CDP) foi construído a partir de uma variável dependente quantitativa aferida por meio da correlação com variáveis independentes (Casos). Neste modelo foram consideradas como variáveis independentes, os Casos com maior 
nível de correlação entre os Nós, bem como maior peso quando a determinância para evidenciação das ações diante das mudanças climáticas (Faria, Andrade, \& Gomes, 2018A). A quantidade de variáveis dependentes levou em consideração o alto poder de explicação do conjunto de casos, medido em função do percentual de cobertura agregado em relação ao total dos fatores.

O modelo proposto para o índice é o seguinte:

IEAMC-CDP $=\left(\mathrm{C}^{*}\right.$ *Peso 1$)+(\mathrm{C} 2 *$ Peso 2$)+($ Cn*Peso $n)$

Onde:

C 1 *Peso 1 = Nós do Caso 1 multiplicado pela média dos pesos dos respectivos Nós do Caso 1;

C2*Peso2= Nós do Caso 2 multiplicado pela média dos pesos dos respectivos Nós do Caso 2;

Cn*Peso $n=$ Nós do Caso $n$ multiplicado pela média dos pesos dos respectivos Nós do Caso $n$.

Com isso, foi possível retornar às informações disponíveis no banco de dados pelas empresas e reavalia-las, classificando-as com um parâmetro construído a partir das informações prestadas pelo conjunto geral das empresas respeitando o limite correlacional entre as variáveis (Nós) identificados. Por fim foi recriado o ranking das empresas avaliadas com base no IEAMC-CDP das empresas brasileiras participantes da amostra, demonstrando aquelas que atingiram o maior índice para o período.

Como resultado desta etapa, foi possível identificar as empresas que mais evidenciaram informações acerca das ações diante das mudanças climáticas no período entre 2014 e 2016. A construção do IEAMC-CDP ainda permitirá reavaliação futura e constante das empresas com frequência anual dependendo das determinantes identificadas no decorrer da pesquisa e disponibilidade dos dados. A Figura 2 resume a estrutura de métodos utilizada nos três trabalhos, sendo dois deles já publicados anteriormente. 
Evidenciação das Ações Diante das Mudanças Climáticas nos Relatórios das Empresas Participantes do Carbon Disclosure Project (CDP) Brasil

\begin{tabular}{|c|c|c|c|}
\hline Etapas Anteriores e Atual & Fonte de Dados & $\begin{array}{c}\text { Técnica de } \\
\text { Tratamento dos } \\
\text { Dados }\end{array}$ & $\begin{array}{l}\text { Pesquisa } \\
\text { publicada } \\
\text { em }\end{array}$ \\
\hline $\begin{array}{l}\text { Identificar os fatores } \\
\text { determinantes da evidenciação } \\
\text { voluntária de informações sobre } \\
\text { enfrentamento das mudanças } \\
\text { climáticas do ponto de vista de } \\
\text { especialistas e gestores } \\
\text { brasileiros. }\end{array}$ & $\begin{array}{l}\text { - Artigos, teses e } \\
\text { dissertações. } \\
\text { - Sítios das } \\
\text { empresas da } \\
\text { amostra. }\end{array}$ & $\begin{array}{l}\text { - Análise descritiva } \\
\text { - Distribuição de } \\
\text { frequência } \\
\text { - Análise estatística } \\
\text { Mann-Whitney Test. }\end{array}$ & $\begin{array}{l}\text { Faria, } \\
\text { Andrade } \\
\text { e Gomes } \\
\text { (2018A) }\end{array}$ \\
\hline $\begin{array}{l}\text { Identificar os fatores } \\
\text { determinantes das ações diante } \\
\text { das mudanças climáticas mais } \\
\text { evidenciados nos relatórios } \\
\text { anuais das empresas brasileiras } \\
\text { participantes do CDP, entre os } \\
\text { anos de } 2014 \text { a } 2016 \text {. }\end{array}$ & $\begin{array}{l}\text { - Relatórios de } \\
\text { Sustentabilidade e } \\
\text { Administração. } \\
\text { - Demonstrações } \\
\text { - Financeiras } \\
\text { - Formulários de } \\
\text { Referência }\end{array}$ & $\begin{array}{l}\text { - Análise } \\
\text { documental } \\
\text { - Percentual de } \\
\text { cobertura (Nvivo®) } \\
\text { - Pontuação (Pont.) } \\
\text { - Distribuição de } \\
\text { frequência }\end{array}$ & $\begin{array}{l}\text { Faria, } \\
\text { Andrade e } \\
\text { Gomes } \\
\text { (2018B) }\end{array}$ \\
\hline $\begin{array}{l}\text { Propor escala para mensuração } \\
\text { do nível de evidenciação das } \\
\text { ações diante das mudanças } \\
\text { climáticas para as empresas do } \\
\text { CDP Brasil a partir da avaliação } \\
\text { atribuída pelos especialistas, } \\
\text { gestores e pela avaliação da } \\
\text { menção nos relatórios anuais. }\end{array}$ & $\begin{array}{l}\text { - Fatores } \\
\text { determinantes da } \\
\text { evidenciação das } \\
\text { ações diante das } \\
\text { mudanças } \\
\text { climáticas }\end{array}$ & $\begin{array}{l}\text { - Análise de Casos } \\
\text { (Nvivo®) } \\
\text { - Índice de } \\
\text { correlação } \\
\text { estatística de } \\
\text { Pearson } \\
\text { - Modelo de cálculo } \\
\text { do IEAMC-CDP Brasil }\end{array}$ & $\begin{array}{l}\text { Não se } \\
\text { aplica. }\end{array}$ \\
\hline
\end{tabular}

Figura 2 - Estrutura de métodos utilizados.

Fonte: Elaboração própria

\section{DESENVOLVIMENTO DA PESQUISA}

O IEAMC-CDP referente às empresas brasileiras calculado para 2014-2016 foi construído a partir da estruturação dos Casos identificados no decorrer da pesquisa na medida em que o pesquisador desenvolvia a coleta de dados nos relatórios anuais. A Tabela 1 apresenta um total de 14 Casos criados na pesquisa, os Nós (fatores determinantes) que compõem cada Caso e o coeficiente de correlação de Pearson calculado pelo software Nvivo®. O software calcula o coeficiente de correlação de Pearson para todos os Nós da amostra, entretanto, apresenta-se na Tabela 1 apenas aqueles que estão relacionados aos Casos criados com o intuito de confirmar a percepção do pesquisador no decorrer da coleta de dados. 
Tabela 1

Casos do Nvivo e Correlação de Pearson

\begin{tabular}{|c|c|c|c|c|c|}
\hline \multirow{2}{*}{$\begin{array}{c}\text { Caso } \\
\mathrm{N}^{\circ}\end{array}$} & \multicolumn{4}{|c|}{ Fatores determinantes } & \multirow{2}{*}{$\begin{array}{l}\text { Correlação } \\
\text { de Pearson }\end{array}$} \\
\hline & 1 & 2 & 3 & 4 & \\
\hline 1 & $\begin{array}{l}\text { Prevenção da } \\
\text { polvição }\end{array}$ & $\begin{array}{l}\text { Prevenção de } \\
\text { perdas }\end{array}$ & - & - & 0,996896 \\
\hline 2 & $\begin{array}{l}\text { Estratégia } \\
\text { empresarial }\end{array}$ & $\begin{array}{l}\text { Estratégia } \\
\text { Mudança Climática }\end{array}$ & - & - & 0,990569 \\
\hline 3 & $\begin{array}{l}\text { Estratégia } \\
\text { Mudança } \\
\text { Climática }\end{array}$ & $\begin{array}{l}\text { Gestão de risco } \\
\text { ambiental }\end{array}$ & - & - & 0,982580 \\
\hline 4 & $\begin{array}{l}\text { Nível de } \\
\text { regulação }\end{array}$ & $\begin{array}{l}\text { Ramo (alto/baixo } \\
\text { impacto) }\end{array}$ & - & - & 0,982225 \\
\hline 5 & $\begin{array}{l}\text { Sistema de Gestão } \\
\text { Ambiental }\end{array}$ & $\begin{array}{l}\text { Gestão de ativos } \\
\text { ambientais }\end{array}$ & - & - & 0,968859 \\
\hline 6 & $\begin{array}{l}\text { Nível de } \\
\text { regulação }\end{array}$ & $\begin{array}{l}\text { Prevenção da } \\
\text { polvição }\end{array}$ & - & - & 0,962980 \\
\hline 7 & $\begin{array}{l}\text { Sistema de Gestão } \\
\text { Ambiental }\end{array}$ & $\begin{array}{l}\text { Gestão de risco } \\
\text { ambiental }\end{array}$ & - & - & 0,961191 \\
\hline 8 & $\begin{array}{l}\text { Ramo (alto/baixo } \\
\text { impacto) }\end{array}$ & $\begin{array}{l}\text { Tamanho da } \\
\text { empresa }\end{array}$ & $\begin{array}{l}\text { Nível de } \\
\text { regulação }\end{array}$ & $\begin{array}{l}\text { Volume de } \\
\text { emissões GEE }\end{array}$ & 0,959315 \\
\hline 9 & $\begin{array}{l}\text { Sistema de Gestão } \\
\text { Ambiental }\end{array}$ & $\begin{array}{l}\text { Certificação } \\
\text { Ambiental }\end{array}$ & - & - & 0,957317 \\
\hline 10 & $\begin{array}{l}\text { Estratégia } \\
\text { empresarial }\end{array}$ & $\begin{array}{l}\text { Pressão dos } \\
\text { stakeholders }\end{array}$ & - & - & 0,955275 \\
\hline 11 & $\begin{array}{l}\text { Volume de } \\
\text { emissões GEE }\end{array}$ & $\begin{array}{l}\text { Estratégia } \\
\text { Mudança Climática }\end{array}$ & - & - & 0,954702 \\
\hline 12 & $\begin{array}{l}\text { Nível de } \\
\text { regulação }\end{array}$ & $\begin{array}{l}\text { Certificação } \\
\text { Ambiental } \\
\end{array}$ & - & - & 0,946806 \\
\hline 13 & $\begin{array}{l}\text { Sistema de Gestão } \\
\text { Ambiental }\end{array}$ & Nível de regulação & - & - & 0,946553 \\
\hline 14 & $\begin{array}{l}\text { Pontuação } \\
\text { Desempenho CDP }\end{array}$ & $\begin{array}{l}\text { Pontuação } \\
\text { Transparência CDP }\end{array}$ & - & - & 0,816585 \\
\hline
\end{tabular}

Fonte: Adaptado Faria, Andrade e Gomes, 2018B

Com base nesta confirmação de correlação entre os Nós nos 14 Casos, foi possível ordenar os casos de acordo com o maior nível de correlação de Pearson, ou seja, o índice 1 corresponde a uma correlação positiva perfeita, ou seja, quanto mais próximo de 1, maior é a correlação entre as variáveis analisadas (Field, 2009). Sendo assim, buscou-se escolher os Casos com os seguintes critérios:

1- Maior índice de correlação de Pearson;

2- Maior \%Cob dos respectivos Nós que o compuseram; e

3- Composição original dos Casos.

Percentual de Cobertura (\%Cob) é calculado pelo Nvivo® e é uma função da quantidade textual direcionada ao determinado Nó pelo total de texto disponível nos relatórios das empresas estudadas. Com isso, buscou-se abranger no modelo os fatores determinantes com maior \%Cob para que, na agregação do modelo, o mesmo pudesse dispor do maior poder de explicação possível. Os 4 Casos escolhidos, compostos por 10 Nós representam juntos $71,52 \%$ (Faria, Andrade, \& Gomes, 2018B) do total de informações evidenciadas nos relatórios anuais diante das mudanças climáticas no período estudado. Este foi o maior 
Evidenciação das Ações Diante das Mudanças Climáticas nos Relatórios das Empresas Participantes do Carbon Disclosure Project (CDP) Brasil

percentual possível com base nos critérios escolhidos para este fim. Sendo assim, a Tabela 2 apresenta os Casos escolhidos.

\section{Tabela 2}

Casos do Nvivo® e Correlação de Pearson - \% de Coberturas

\begin{tabular}{|c|c|c|c|c|c|c|c|c|}
\hline \multirow[t]{3}{*}{$\begin{array}{l}\mathrm{Ca} \\
\text { sos }\end{array}$} & \multicolumn{4}{|c|}{ Fatores determinantes } & \multirow{2}{*}{\multicolumn{2}{|c|}{$\begin{array}{c}\text { Correlação de } \\
\text { Pearson }\end{array}$}} & \multirow{3}{*}{$\begin{array}{c}\text { Freq. } \\
\text { Acum. } \\
\text { \%Cob.* }\end{array}$} & \multirow{3}{*}{$\begin{array}{c}\text { Freq. Acum. } \\
\text { \%Cob.** } \\
\%\end{array}$} \\
\hline & 1 & 2 & 3 & 4 & & & & \\
\hline & $\%$ Cob. & $\%$ Cob. & $\%$ Cob. & $\%$ Cob. & Média & D.Pad & & \\
\hline \multirow[t]{2}{*}{1} & $\begin{array}{l}\text { Prevenção } \\
\text { da polvição }\end{array}$ & $\begin{array}{l}\text { Prevenção } \\
\text { de perdas }\end{array}$ & - & - & 0,996896 & \multirow[b]{2}{*}{0,0127} & \multirow[b]{2}{*}{0,6891} & \\
\hline & 0,3535 & 0,3356 & & & 0,3445 & & & $23,97 \%$ \\
\hline \multirow[t]{2}{*}{2} & $\begin{array}{l}\text { Estratégia } \\
\text { empresarial }\end{array}$ & $\begin{array}{l}\text { Estratégia } \\
\text { Mudança } \\
\text { Climática }\end{array}$ & - & - & 0,990569 & \multirow[b]{2}{*}{0,0593} & \multirow[b]{2}{*}{1,0292} & \multirow[b]{2}{*}{$35,80 \%$} \\
\hline & 0,1281 & 0,2120 & & & 0,1700 & & & \\
\hline \multirow[t]{2}{*}{5} & $\begin{array}{l}\text { Sistema de } \\
\text { Gestão } \\
\text { Ambiental }\end{array}$ & $\begin{array}{l}\text { Gestão de } \\
\text { ativos } \\
\text { ambientais }\end{array}$ & - & - & 0,968859 & \multirow[b]{2}{*}{0,0521} & \multirow[b]{2}{*}{1,4929} & \multirow[b]{2}{*}{$51,93 \%$} \\
\hline & 0,1950 & 0,2687 & & & 0,2318 & & & \\
\hline \multirow[t]{2}{*}{8} & $\begin{array}{l}\text { Ramo } \\
\text { (alto/baixo } \\
\text { impacto) }\end{array}$ & $\begin{array}{l}\text { Tamanho } \\
\text { da } \\
\text { empresa }\end{array}$ & $\begin{array}{l}\text { Nível de } \\
\text { regulação }\end{array}$ & $\begin{array}{l}\text { Volume } \\
\text { de } \\
\text { emissões } \\
\text { GEE }\end{array}$ & 0,959315 & \multirow[b]{2}{*}{0,1007} & \multirow[b]{2}{*}{2,0560} & \multirow[b]{2}{*}{$71,52 \%$} \\
\hline & 0,1562 & 0,0262 & 0,1124 & 0,2683 & 0,1407 & & & \\
\hline
\end{tabular}

*Frequência acumulada do \%Cob. dos Nós nos respectivos

Casos.

**Total do \%Cob. geral $=2,8746$

Fonte: Dados da pesquisa

O Desvio Padrão é uma referência de proximidade das variáveis em relação à média, ou seja, mede a qualidade da média como valor representativo das variáveis. Quanto maior o valor do Desvio Padrão, maior a distância dos valores medidos em relação à média (Field, 2009). Sendo assim, e considerando os altos valores (em relação à média) apresentados dos desvios padrão para os fatores em cada Caso, para a construção dos IEAMC-CDP decidiu-se inserir as variáveis separadamente e não apenas a média entre as variáveis.

A utilização em separado apresenta uma composição mais clara de cada variável do índice bem como aumenta o poder de predição do modelo. 0 mesmo procedimento foi aplicado aos pesos dos Nós (fatores determinantes) nos respectivos Casos escolhidos, conforme a Tabela 3. 
Tabela 3

Casos e Correlação de Pearson - Peso dos Especialistas, Gestores (Questionários e Entrevista)

\begin{tabular}{|c|c|c|c|c|c|c|}
\hline \multirow[t]{3}{*}{ Casos } & \multicolumn{4}{|c|}{ Fatores determinantes } & \multicolumn{2}{|c|}{$\begin{array}{c}\text { Correlação } \\
\text { Pearson }\end{array}$} \\
\hline & 1 & 2 & 3 & 4 & & \\
\hline & Peso & Peso & Peso & Peso & Média & $\begin{array}{c}\text { D.Pad } \\
\text {. }\end{array}$ \\
\hline \multirow[t]{2}{*}{1} & $\begin{array}{l}\text { Prevenção da } \\
\text { polvição }\end{array}$ & $\begin{array}{l}\text { Prevenção de } \\
\text { perdas }\end{array}$ & - & - & 0,996896 & \\
\hline & 3,5175 & 3,2096 & & & 3,3635 & 0,2177 \\
\hline \multirow[t]{2}{*}{2} & $\begin{array}{l}\text { Estratégia } \\
\text { empresarial }\end{array}$ & $\begin{array}{l}\text { Estrat.Mud.Climáti } \\
\text { ca }\end{array}$ & - & - & 0,990569 & \\
\hline & 4,102 & 4,4274 & & & 4,2647 & 0,2301 \\
\hline \multirow[t]{2}{*}{5} & $\begin{array}{l}\text { Sistema Gestão } \\
\text { Amb. }\end{array}$ & $\begin{array}{l}\text { Gestão At. } \\
\text { ambientais }\end{array}$ & - & - & 0,968859 & \\
\hline & 3,5983 & 4,0165 & & & 3,8074 & 0,2957 \\
\hline \multirow[t]{2}{*}{8} & $\begin{array}{l}\text { Ramo (alto/baixo } \\
\text { impacto) }\end{array}$ & $\begin{array}{l}\text { Tamanho da } \\
\text { empresa }\end{array}$ & $\begin{array}{l}\text { Nível } \\
\text { Regulação }\end{array}$ & $\begin{array}{l}\text { Volume de } \\
\text { emissões GEE }\end{array}$ & 0,959315 & \\
\hline & 3,9118 & 3,2564 & 4,1829 & 4,0533 & 3,8511 & 0,4116 \\
\hline
\end{tabular}

Fonte: Dados da pesquisa

Considerando os baixos valores dos desvios padrão calculados em relação ao valor da média dos pesos calculados de cada Nó, para efeito de composição estrutural do IEAMC-CDP, pode-se utilizar a média dos pesos, neste caso, chamada de "Peso Combinado". Conforme modelo proposto e sendo conhecidos dos Casos e Pesos Combinados, apresenta-se o modelo do IEAMCCDP:

$$
\begin{aligned}
& Y=[(\% \text { Cob. PPo+ \%Cob. PPe) * PC (Caso 1)] + } \\
& \text { [(\%Cob. EEm + \%Cob. EMC) *PC (Caso 2)] + } \\
& \text { [(\%Cob. SGA + \%Cob. GAA) *PC (Caso 5)] + } \\
& \text { [(\%Cob. Ra + \%Cob. Tm + \%Cob. NRe + \%Cob. VGEE) * PC (Caso 8) ] }
\end{aligned}
$$

Onde,

$Y=$ Variável dependente.

PPo $=$ fator Prevenção Polvição.

$P P e=$ fator Prevenção de Perdas.

$\mathrm{EEm}=$ fator Estratégia Empresarial.

$E M C$ = fator Estratégia Mudança Climática.

$S G A=$ fator Sistema de Gestão Ambiental.

$S G A=$ fator Gestão de Ativos Ambientais.

$R a=$ fator Ramo de atividade.

Tm = fator Tamanho da empresa

NRe = fator Nível de Regulação

VGEE = Fator Volume de Emissões GEE.

$P C=$ Peso Combinado. 
A partir da construção do modelo foi possível aplicá-lo na base de dados disponível na pesquisa de modo a mensurar o nível de evidenciação das ações diante das mudanças climáticas das 48 empresas cujos relatórios anvais foram utilizados nesta pesquisa. Com isso, foi possível reclassificar as empresas da amostra com base no IEAMC-CDP calculado individualmente. A Tabela 4 demonstra a reclassificação das empresas ordenado de acordo com o maior IEAMC-CDP, bem como o comparativo com os resultados disponibilizados nas pesquisas anteriores apresentadas na Figura 2.

Na Tabela 4, coluna Geral, consta a posição de cada empresa calculada com base na avaliação de importância do fator determinante atribuída por especialistas e gestores. Para se alcançar este resultado cada fator foi submetido à avaliação ao mapeamento nos relatórios anuais por meio do software Nvivo®, gerando uma pontuação capaz de classificar os fatores. Juntamente com esta etapa, foi possível classificar também as empresas uma vez que a pontuação calculada pode ser atribuída a cada empresa participante da pesquisa (Faria, Andrade, \& Gomes, 2018B).

Ainda na Tabela 4, os resultados apresentados na coluna IEAMC-CDP representam a pontuação de cada empresa proveniente da aplicação do método proposto para avaliação das empresas da pesquisa. Com isso foi possível perceber a viabilidade do índice em representar os resultados gerais obtidos quando foram analisados todos os 32 fatores determinantes. As variações por empresa representam oportunidades de ampliação dos estudos quanto ao uso dos fatores determinantes da evidenciação das ações diante das mudanças climáticas. 
Tabela 4

Resultado do IEAMC-CDP para empresas da amostra

\begin{tabular}{|c|c|c|c|c|c|c|c|c|c|c|c|}
\hline Empresas & Ramos & Geral* & $\begin{array}{l}\text { IEAMC } \\
\text { CDP** }\end{array}$ & Var. & \begin{tabular}{|l|} 
Dif. $\mid$ \\
$* * *$
\end{tabular} & Empresas & Ramos & Geral* & $\begin{array}{l}\text { IEAMC } \\
\text { CDP** }\end{array}$ & Var. & $\underset{* * *}{\mid \text { Dif. }}$ \\
\hline ALL & Transporte & 2 & 1 & $\uparrow$ & 1 & Copasa & $\begin{array}{l}\text { Dist. de Água e } \\
\text { Saneamento } \\
\end{array}$ & 30 & 25 & $\uparrow$ & 5 \\
\hline B2W & $\begin{array}{l}\text { Varejo } \\
\text { Eletrônico }\end{array}$ & 1 & 2 & $\downarrow$ & 1 & $\begin{array}{l}\text { Cia } \\
\text { Paraense } \\
\text { de } \\
\text { Energia - } \\
\text { COPEL }\end{array}$ & $\begin{array}{l}\text { Dist. de energia } \\
\text { elétrica }\end{array}$ & 27 & 26 & $\uparrow$ & 1 \\
\hline Cia Energ. SP - CESP & $\begin{array}{l}\text { Dist. de energia } \\
\text { elétrica }\end{array}$ & 9 & 3 & 个 & 6 & $\begin{array}{l}\text { BM\&F } \\
\text { Bovespa }\end{array}$ & \begin{tabular}{|l} 
Bancos e \\
Instituições \\
Financeiras \\
\end{tabular} & 29 & 27 & $\uparrow$ & 2 \\
\hline $\begin{array}{l}\text { Cia Bras. De Dist. (CBD) } \\
\text { Pão de Açúcar }\end{array}$ & Varejo & 11 & 4 & 个 & 7 & $\begin{array}{l}\text { BRF Brasil } \\
\text { Foods } \\
\end{array}$ & Alimentos & 26 & 28 & $\downarrow$ & 2 \\
\hline VALE & $\begin{array}{l}\text { Metais e } \\
\text { Mineração }\end{array}$ & 8 & 5 & 个 & 3 & $\begin{array}{l}\text { BICBanc } \\
0\end{array}$ & \begin{tabular}{|l} 
Bancos e \\
Instituições \\
Financeiras \\
\end{tabular} & 21 & 29 & $\downarrow$ & 8 \\
\hline CPFL Energia & \begin{tabular}{|l|} 
Dist. de energia \\
elétrica \\
\end{tabular} & 3 & 6 & $\downarrow$ & 3 & WEG & $\begin{array}{l}\text { Máquinas e } \\
\text { Equipamentos }\end{array}$ & 34 & 30 & $\uparrow$ & 4 \\
\hline CELESC & $\begin{array}{l}\text { Dist. de energia } \\
\text { elétrica }\end{array}$ & 7 & 7 & 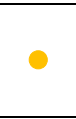 & - & $\begin{array}{l}\text { TIM } \\
\text { Participa } \\
\text { ções } \\
\end{array}$ & $\begin{array}{l}\text { Telecomunicaç } \\
\text { ões }\end{array}$ & 19 & 31 & $\downarrow$ & 12 \\
\hline Banco Bradesco & \begin{tabular}{|l|} 
Bancos e \\
Instituições \\
Financeiras
\end{tabular} & 5 & 8 & $\downarrow$ & 3 & JBS & Alimentos & 33 & 32 & $\boldsymbol{\uparrow}$ & 1 \\
\hline COSAN & $\begin{array}{l}\text { Óleo, Gás e } \\
\text { Combustíveis }\end{array}$ & 12 & 9 & $\uparrow$ & 3 & \begin{tabular}{|l|} 
Lojas \\
Renner
\end{tabular} & Varejo & 31 & 33 & $\downarrow$ & 2 \\
\hline AES Tietê & $\begin{array}{l}\text { Dist. de energia } \\
\text { elétrica }\end{array}$ & 6 & 10 & $\downarrow$ & 4 & $\begin{array}{l}\text { Cyrela } \\
\text { Brazil } \\
\text { Realty }\end{array}$ & $\begin{array}{l}\text { Mercado } \\
\text { Imobiliário }\end{array}$ & 36 & 34 & $\uparrow$ & 2 \\
\hline Cemig & $\begin{array}{l}\text { Dist. de energia } \\
\text { elétrica }\end{array}$ & 13 & 11 & $\uparrow$ & 2 & $\begin{array}{l}\text { Itaú S.A. } \\
\text { Investime } \\
\text { ntos }\end{array}$ & \begin{tabular}{|l} 
Bancos e \\
Instituições \\
Financeiras
\end{tabular} & 32 & 35 & $\downarrow$ & 3 \\
\hline Fibria & Celulose & 4 & 12 & $\downarrow$ & 8 & $\begin{array}{l}\text { Duke } \\
\text { Paranap } \\
\text { anema }\end{array}$ & $\begin{array}{l}\text { Dist. de energia } \\
\text { elétrica }\end{array}$ & 37 & 36 & $\uparrow$ & 1 \\
\hline
\end{tabular}


Tabela 4

Resultado do IEAMC-CDP para empresas da amostra

\begin{tabular}{|c|c|c|c|c|c|c|c|c|c|c|c|}
\hline Empresas & Ramos & Geral* & $\begin{array}{l}\text { IEAMC } \\
\text { CDP** }\end{array}$ & Var. & $\mid \begin{array}{l}\text { Dif. } \\
* * * \\
\end{array}$ & Empresas & Ramos & Geral* & $\begin{array}{l}\text { IEAMC } \\
\text { CDP** }\end{array}$ & Var. & $\mid \begin{array}{c}\mid \text { Dif. } \\
* * *\end{array}$ \\
\hline Duratex & Celulose & 15 & 13 & $\uparrow$ & 2 & $\begin{array}{l}\text { Santand } \\
\text { er Brasil }\end{array}$ & \begin{tabular}{|l} 
Bancos e \\
Instituições \\
Financeiras \\
\end{tabular} & 35 & 37 & $\downarrow$ & 2 \\
\hline Petrobrás & $\begin{array}{l}\text { Óleo, Gás e } \\
\text { Combustíveis }\end{array}$ & 16 & 14 & $\uparrow$ & 2 & Marfrig & Alimentos & 40 & 38 & $\uparrow$ & 2 \\
\hline Klabin & Celulose & 10 & 15 & $v$ & 5 & CCR & $\begin{array}{l}\text { Dist. de energia } \\
\text { elétrica }\end{array}$ & 38 & 39 & $\downarrow$ & 1 \\
\hline AES Eletropaulo & $\begin{array}{l}\text { Dist. de energia } \\
\text { elétrica }\end{array}$ & 14 & 16 & $\Downarrow$ & 2 & Natura & $\begin{array}{l}\text { Higiene e } \\
\text { Cuidados } \\
\text { Pessoais } \\
\end{array}$ & 42 & 40 & $\uparrow$ & 2 \\
\hline Banco do Brasil & \begin{tabular}{|l|} 
Bancos e \\
Instituições \\
Financeiras
\end{tabular} & 23 & 17 & $\uparrow$ & 6 & $\begin{array}{l}\text { Grupo } \\
\text { Fleury }\end{array}$ & $\begin{array}{l}\text { Serviços de } \\
\text { Saúde }\end{array}$ & 41 & 41 & - & - \\
\hline Light & $\begin{array}{l}\text { Dist. de energia } \\
\text { elétrica }\end{array}$ & 18 & 18 & 0 & - & EDP & $\begin{array}{l}\text { Óleo, Gás e } \\
\text { Combustíveis }\end{array}$ & 39 & 42 & $\downarrow$ & 3 \\
\hline Porto Seguro & Seguros & 20 & 19 & $\uparrow$ & 1 & $\begin{array}{l}\text { Lojas } \\
\text { America } \\
\text { nas }\end{array}$ & Varejo & 43 & 43 & - & - \\
\hline Braskem & Química & 17 & 20 & $\downarrow$ & 3 & \begin{tabular}{|l|} 
Itaú \\
Unibanc \\
o Holding \\
\end{tabular} & \begin{tabular}{|l} 
Bancos e \\
Instituições \\
Financeiras \\
\end{tabular} & 45 & 44 & $\uparrow$ & 1 \\
\hline Eletrobrás & $\begin{array}{l}\text { Dist. de energia } \\
\text { elétrica }\end{array}$ & 22 & 21 & $\uparrow$ & 1 & \begin{tabular}{|l|} 
Anhangu \\
era \\
Kroton \\
\end{tabular} & $\begin{array}{l}\text { Serviços ao } \\
\text { Consumidor } \\
\text { (Educação) } \\
\end{array}$ & 44 & 45 & $\downarrow$ & 1 \\
\hline Cielo & Software & 24 & 22 & 个 & 2 & \begin{tabular}{|l|} 
Ultrapar \\
Participa \\
ções \\
\end{tabular} & $\begin{array}{l}\text { Óleo, Gás e } \\
\text { Combustíveis }\end{array}$ & 46 & 46 & - & - \\
\hline Oi S.A. & \begin{tabular}{|l|} 
Telecomunicaç \\
ões \\
\end{tabular} & 28 & 23 & $\uparrow$ & 5 & $\begin{array}{l}\text { Odontop } \\
\text { rev }\end{array}$ & $\begin{array}{l}\text { Serviços de } \\
\text { Saúde }\end{array}$ & 48 & 47 & $\uparrow$ & 1 \\
\hline Ecorodovias & Transporte & 25 & 24 & $\uparrow$ & 1 & $\begin{array}{l}\text { BRMALLS } \\
\text { Partipaç } \\
\text { ões } \\
\end{array}$ & $\begin{array}{l}\text { Mercado } \\
\text { Imobiliário }\end{array}$ & 47 & 48 & $\downarrow$ & 1 \\
\hline
\end{tabular}

* Posição de cada empresa calculada até a etapa anterior da pesquisa.

** Posição de cada empresa calculada baseada no IEAMC-CDP.

*** Diferença entre as posições anteiror e atual, em módulo.

Fonte: Elaboração própria 
O resultado da aplicação do IEAMC-CDP apresenta a empresa ALL (Transportes) como destaque no período, seguida pela B2W (e-commerce) e a CESP (Energia) em terceiro lugar. Este resultado confirma resultados na literatura que apresenta setores como os de transporte e geração de energia como grandes produtores de GEE devido às características peculiares das suas atividades. Entretanto, destaca-se o ramo de e-commerce como um achado neste contexto como um ramo de atividade com alto volume de evidenciação das ações diante das mudanças climáticas mesmo não considerado um ramo altamente polvente pela literatura (Faria, Andrade, \& Gomes, 2018B). A empresa B2W, destaque nesta pesquisa, atua no comércio eletrônico, foi criada no final de 2006 pela fusão de sites (Submarino, Shoptime, Americanas.com) de comércio digital, passando a ser líder na América Latina além de ter recebido recentemente a certificação LEED® (Leadership in Energy and Environmental Design) na categoria Silver e o Prêmio Ambiental Chico Mendes.

A pontuação do IEAMC-CDP também pode ser apresentada por ramo de atividade. A Figura 3 apresenta a pontuação IEAMC-CDP das empresas agrupadas por ramos permitindo a comparação com a pontuação geral obtida relacionando todos os fatores (Pont.) apresentado por Faria, Andrade e Gomes (2018B). 


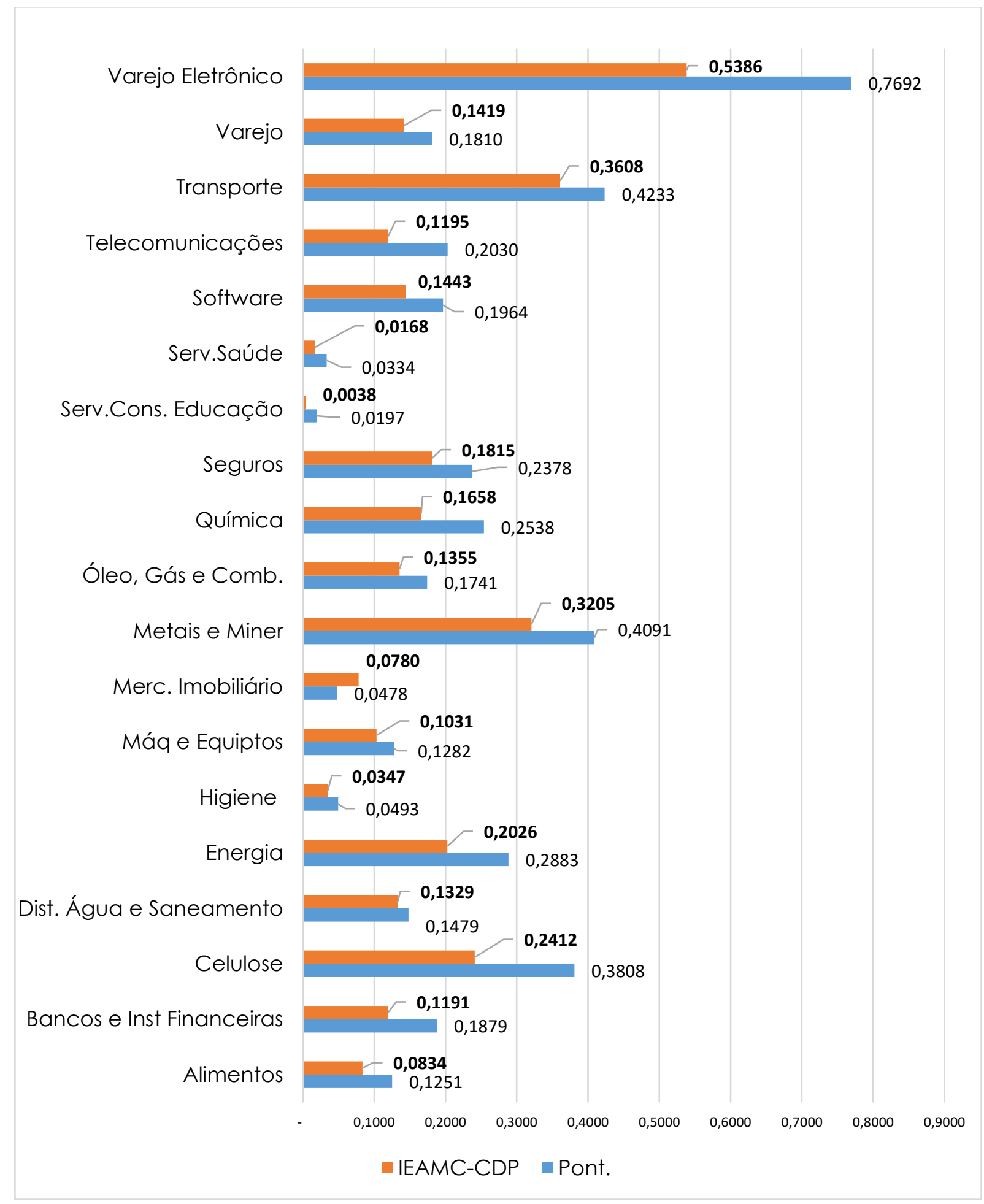

Figura 3 - Pontuação IEAMC-CDP das empresas agrupadas por ramos. Pont. = Resultado apresentado por Faria, Andrade e Gomes (2018B) Fonte: Dados da pesquisa.

O IEAMC-CDP acompanhou a tendência da pontuação geral (Pont.), o que demonstra que o índice espelha o volume completo de dados com os 32 fatores. Com isso, é possível inferir que o modelo conseguiu perceber os principais fatores determinantes da evidenciação das ações diante das mudanças climáticas em sua estrutura. Além disso, no momento de aplicação do modelo 
em sociedades diversas da amostra o questionário deve ser reaplicado em grupos sociais (gestores e especialistas) nas respectivas sociedades no qual se deseja mensurar a evidenciação, haja vista que a expectativa de determinada sociedade quanto ao peso dos fatores determinantes pode ser diferente da amostra. Isso permite uma flexibilização e adaptação do modelo de modo a permitir-se perceber tais necessidades específicas de cada sociedade e assim refletir no resultado do IEAMC-CDP adequado às necessidades de informação daquele grupo social.

Segundo Machado e Ott (2015), no Brasil, as empresas produzem evidenciações por meio dos relatórios anuais relatando ações que visem popularizar seus modelos, fazer adeptos à sua forma de gestão, cooptar integrantes para desenvolver ações ambientais e mostrar que produzem resultados ambientalmente adequados. Por esse motivo este trabalho identificou os fatores determinantes da evidenciação das ações diante das mudanças climáticas, portanto, dos padrões de comportamento utilizados, permitindo análise numa perspectiva ex ante e ex post.

Ao identificar os fatores determinantes divulgados nos relatórios anuais das empresas participantes da pesquisa também foi possível identificar as informações divulgadas aos stakeholders. Por sua vez, mostram também o desejo atendido das informações demandadas pelos stakeholders. Neste trabalho, este processo ocorreu por meio de uma análise ex ante, de modo a conhecer os fatores determinantes. Por meio de uma proposta numa visão ex post, de modo informar às empresas quais os fatores determinantes das evidenciações as ações diante das mudanças climáticas mais significativos classificados com base no volume de informação apresentado nos relatórios ponderados pelo peso atribuído por especialistas e gestores. Sendo assim, pode-se afirmar que os fatores determinantes contribuem para a identificação de um caminho para a legitimação (conquista ou manutenção) por meio da evidenciação das ações diante das mudanças climáticas.

A proposta estrutural resultante da análise geral do trabalho na qual demonstra, à luz da Teoria da Legitimidade e do reconhecido papel dos stakeholders em todo o processo de evidenciação, o papel dos fatores determinantes. Estes foram identificados na literatura, atribuídos pesos com base na opinião de gestores e especialistas, avaliados com base nos relatórios anuais (obrigatórios e voluntários) e referendados por meio de entrevistas aos gestores. Como produto (ex post), os fatores determinantes foram consolidados numa classificação de relevância para a amostra estudada no qual permite inferir aqueles que devem fazer parte das evidenciações por meio dos relatórios anuais. Por fim, foi construído o IEAMC-CDP que, por sua vez, foi aplicado na base de dados disponível, permitindo identificar as empresas que se destacaram quanto ao volume de evidenciação.

Os resultados do IEAMC-CDP representaram $71,52 \%$ do percentual de cobertura dos relatórios estudados, uma vez que foram identificados os 14 fatores determinantes em destaque além da identificação das correlações entre eles por meio dos 4 Casos percebidos pelo pesquisador e confirmados pelo coeficiente de correlação de Pearson. Considerando a perspectiva de Suchman (1995) no qual afirma que a legitimidade é uma percepção de que as ações de uma organização são desejáveis, próprias ou apropriadas dentro de algum sistema social de normas, valores, crenças e definições, pode-se afirmar que o processo 
Evidenciação das Ações Diante das Mudanças Climáticas nos Relatórios das Empresas Participantes do Carbon Disclosure Project (CDP) Brasil

de construção do IEAMC-CDP permitiu atribuir ao mesmo a representatividade, ainda que parcial, do sistema social de normas, valores, crenças e definições inerentes às empresas do CDP Brasil.

Segundo Dias Filho (2012) parte-se do princípio de que elas (as empresas) se legitimam na medida em que conseguem alinhar suas práticas com as normas e padrões de comportamento defendidos no ambiente em que operam. Por acreditar que foi possível perceber parte do padrão de evidenciação nas empresas do CDP Brasil pode-se afirmar que o IEAMC-CDP é um instrumento de aferição de parte da legitimidade pois explica, por meio dos fatores determinantes que o compõe, quais os elementos esperados que façam parte das evidenciações pela sociedade e, com base nestes elementos, avalia os resultados apresentados pelas empresas à sociedade, ou seja, o alinhamento da prática de evidenciação no ambiente em que operam.

Como princípio da construção do modelo de avaliação cabe a recomendação quando a revalidação dos pesos atribuídos a cada fator determinante (Faria, Andrade, \& Gomes, 2018A), a cada 5 anos ou a cada evento mundial ou local significativo que possa vir a alterar as percepções da sociedade quanto ao peso dos fatores determinantes. Além disso, o método de avaliação do IEAMC-CDP permite uma flexibilização e adaptação do modelo de modo a permitir-se perceber as necessidades específicas de casa sociedade possam ser alteradas a partir da alteração dos fatores determinantes, desde que sejam seguidos os mesmos procedimentos de identificação aplicados nesta pesquisa.

Empresas que mais evidenciam, tendem a atrair mais investidores para seus negócios, entretanto, além do volume, as informações pautadas na ética, devem transmitir e permitir o conhecimento sobre suas práticas diante das mudanças climáticas. Neste processo, considera-se que as empresas interessadas em atrair mais investidores, têm desenvolvido mais práticas de enfrentamento (adaptação, mitigação ou ambas) diante das mudanças climáticas e buscam evidenciá-las. Por sua vez o IEAMC-CDP proporciona contribuições para as empresas participantes da pesquisa (e também para aquelas que venham utilizar o índice) pois dispõem de um feedback acerca do seu nível de evidenciação mais amplo do que os índices disponíveis na atualidade.

Considerando que os stakeholders prezam pelas empresas com maior volume de evidenciação sobretudo acerca da sua performance diante das metas ambientais (Sullivan \& Gouldson, 2012; Zhang \& Liu, 2020), estas poderão adaptar estruturas e procedimentos de modo a melhorar sua colocação no índice, consequentemente, ampliando o volume, a qualidade das informações evidenciadas. Assim, os stakeholders poderão ser beneficiados com a ação das empresas neste processo, pois terão disponíveis o IEAMC-CDP, como mais um parâmetro no processo de avaliação das empresas para tomada de decisão.

Se a continuidade de uma organização depende da capacidade de atuar em sintonia com as expectativas da sociedade (expressos com base nos fatores determinantes), é de esperar que ela se esforce para que as suas atividades (inclusive os fatores determinantes de sua evidenciação) sejam aceitas e percebidas como legítimas (Eugénio, 2010; Dias Filho, 2012; Rossoni, 2016, Deegan, 2017). Com isso, é possível predizer os fatores determinantes do processo de evidenciação das ações diante das mudanças climáticas, que neste 
caso, contribuem parcialmente no processo de legitimação no Brasil, haja vista as empresas dependem do reconhecimento social quanto a legitimidade de suas práticas para manter a continuidade. Esta indicação parcial é explicada pelo fato da legitimidade de uma empresa ser medida pelo amplo conjunto de valores de uma sociedade como reconhecimento social, valor da marca, nível de aceitação social, representatividade social, entre outros aspectos que não fizeram parte dos objetivos deste trabalho

\section{CONCLUSÕES E RECOMENDAÇÕES PARA FUTUROS ESTUDOS}

O objetivo foi propor o IEAMC-CDP para mensuração do nível de evidenciação das ações diante das mudanças climáticas para as empresas do CDP Brasil a partir da avaliação atribuída pelos especialistas, gestores e pela avaliação da menção nos relatórios anuais. Como a continuidade de uma organização depende da capacidade de atuar em sintonia com as expectativas da sociedade, é de esperar que ela se esforce para que as suas atividades sejam aceitas e percebidas como legítimas (Deegan, 2002; Deegan, 2017).

Esta sintonia é apresentada na classificação dos fatores determinantes das ações diante das mudanças climáticas pois reflete as opções das empresas em privilegiar, em seu processo de evidenciação, a prevenção da poluição, volume de emissões de GEE, gestão de ativos ambientais, prevenção de perdas, estratégica de mudança climática, sistema de gestão ambiental, ramo de atividade, estratégia empresarial, nível de regulação e tamanho da empresa (Faria, Andrade, \& Gomes, 2018B). Os fatores determinantes indicam quais são os valores relacionados com as ações diante das mudanças climáticas nas empresas brasileiras da amostra os quais são válidos com base no fato de que tais empresas conseguem manter o seu contrato social, tendo seu comportamento com a preservação de recursos, benefícios sociais, produtos e serviços aceitos pela sociedade.

O IEAMC-CDP representa um mecanismo capaz de classificar o nível de evidenciação das ações diante das mudanças climáticas para as empresas do CDP Brasil sendo composto por fatores que representaram $71,52 \%$ de todas as referências principalmente utilizadas nos relatórios anuais no período estudado. $O$ resultado da aplicação do método inerente ao IEAMC-CDP nos dados disponíveis da amostra apresenta a empresa América Latina Logística (ALL) como destaque no período seguida pela $\mathrm{B} 2 \mathrm{~W}$, do ramo de e-commerce.

Apresentou-se os fatores determinantes da evidenciação das ações diante das mudanças climáticas de modo a suprir parte da necessidade dos stakeholders quanto a maior volume de informações sobre o tema. O IEAMC-CDP foi proposto a partir dos fatores determinantes identificados de modo a contribuir para atendimento da necessidade das empresas (sobretudo as grandes empresas participantes do CDP) de manterem a legitimidade (contrato social) no mercado por meio, dentre outros aspectos, da evidenciação de informações que possam atender ao interesse dos stakeholders. Empresas fora da amostra podem utilizar O IEAMC uma vez que os relatórios anuais formam a base de dados de coleta de dados que, por sua vez, é comum às demais empresas de grande porte. 
Evidenciação das Ações Diante das Mudanças Climáticas nos Relatórios das Empresas Participantes do Carbon Disclosure Project (CDP) Brasil

Os fatores determinantes indicam quais são os valores relacionados com as ações diante das mudanças climáticas nas empresas brasileiras da amostra os quais são válidos com base no fato de que tais empresas conseguem manter o seu contrato social, tendo seu comportamento com a preservação de recursos, benefícios sociais, produtos e serviços aceitos pela sociedade. Com os resultados desta pesquisa também foi possível suprir parte da lacuna existente na Teoria da Legitimidade de modo que aponta, especificamente, quais os fatores que podem fazer parte dos relatórios anuais das empresas que atuam no CDP Brasil.

Além de trabalhar com empresas do CDP Brasil as escolhas dos procedimentos metodológicos representam neles próprias limitações naturais, entretanto necessárias à pesquisa, haja vista que outras metodologias podem apresentar novas informações sobre o objeto de estudo e assim, lançar luz nas discussões sobre evidenciação das ações diante das mudanças climáticas.

Os fatores determinantes indicam quais valores estão sendo demandados pela sociedade no Brasil, entretanto esta pesquisa não aprofunda na avaliação do volume necessário de informações e nem na avaliação do nível de satisfação dos stakeholders quando aos volumes apresentados, representando assim uma oportunidade de pesquisa. Além disso, sugere-se desenvolver estudos levando em consideração que a limitação dos fatores escolhidos conduz à discussão que a aceitação social de uma empresa pode não ser plena pois não depende apenas da evidenciação, o que sugere a existência de uma faixa de aceitação mediante possíveis partes de uma aceitação global, composta por outros valores socialmente construídos que vão além da evidenciação das ações diante das mudanças climáticas.

\section{REFERÊNCIAS}

Akbaş, H. E., \& Canikli, S. (2018). Determinants of Voluntary Greenhouse Gas Emission Disclosure: An Empirical Investigation on Turkish Firms. Sustainability, 11 (1), 1-24.DOI: https://doi.org/10.3390/su 11010107

Amran, A., Periasamy, V., \& Zulkafli, A. H. (2014). Determinants of climate change disclosure by developed and emerging countries in Asia Pacific. Sustainable Development, 22(3), 188-204. DOl: https://doi.org/10.1002/sd.539

Antal, M., \& Van den Bergh, J. C. (2013). Macroeconomics, financial crisis and the environment: Strategies for a sustainability transition. Environmental Innovation and Societal Transitions, 6, 47-66. DOI: https://doi.org/10.1016/j.eist.2013.01.002

Barakat, S. R., Freitas, L. P., Boaventura, J. M. G., \& MacLennan, M. L. F. (2016). Legitimidade: uma análise da evolução do conceito na teoria dos stakeholders. Ciencias da Administraçao, 18(44), 66-80. DOI: https://doi.org/10.5007/2175-8077.2016v18n44p66

Barros, C. L. M., \& da Silva Monteiro, S. M. (2012). Determinant factors of mandatory environmental reporting: the case of Portuguese primary metal and steel industry. In Soft Computing in Management and Business Economics (pp. 123- 
147). Springer, Berlin, Heidelberg. DOI: https://doi.org/10.1007/978-3-642-304576_9

Begum, R. A., \& Pereira, J. J. (2015). The awareness, perception and motivational analysis of climate change and business perspectives in Malaysia. Mitigation and Adaptation Strategies for Global Change, 20(3), 361-370. DOI: https://doi.org/10.1007/s1 1027-013-9495-6

Birnik, A. (2013). Developing climate change strategy: A framework for managers. Thunderbird International Business Review, 55(6), 699-717. DOI: https://doi.org/10.1002/tie.21585

Braam, G. J., de Weerd, L. U., Hauck, M., \& Huijbregts, M. A. (2016). Determinants of corporate environmental reporting: The importance of environmental performance and assurance. Journal of cleaner production, 129, 724-734. DOI: https://doi.org/10.1016/j.jclepro.2016.03.039

Burgwal, D. V. D., \& Vieira, R. J. O. (2014). Determinantes da divulgação ambiental em companhias abertas holandesas. Revista Contabilidade \& Finanças, 25(64), 60-78. DOl: https://doi.org/10.1590/\$1519-70772014000100006

Cdp. (2014). CARBON DISCLOSURE PROJECT. Brasil. Disponível em:<http://< www.cdproject.net>. Acesso em: 10 mai. 2014

Conceição, S. H., Dourado, G. B., \& Silva, S. F. (2012). Global Reporting Initiative (GRI)-um estudo exploratório da prática de evidenciação em sustentabilidade empresarial na américa latina. Revista de Gestão, Finanças e Contabilidade, 2(3), 17-38.

Correa, J. C., Gonçalves, M. N., \& de Oliveira Moraes, R. (2015). Disclosure ambiental das companhias do setor de petróleo, gás e biocombustiveis listadas na BM\&FBovespa: uma análise à luz da Teoria da Legitimidade. Revista de Gestão Ambiental e Sustentabilidade, 4(3), 139-154. DOl: 10.5585/geas.v4i3.254

Cotter, J., \& Najah, M. M. (2012). Institutional investor influence on global climate change disclosure practices. Australian journal of management, 37(2), 169 187. DOI: https://doi.org/10.1177/0312896211423945

Deegan, C. (2002). The legitimising effect of social and environmental disclosuresa theoretical foundation. Accounting, Auditing \& Accountability Journal, 15(3), 282-31 1. DOl: https://doi.org/10.1108/09513570210435852

Deegan, C., \& Rankin, M. (1996). Do Australian companies report environmental news objectively? Accounting, auditing \& accountability journal, 9(2): p. 5067. DOl: https://doi.org/10.1108/09513579610116358

Deegan, C. (2017). Twenty five years of social and environmental accounting research within Critical Perspectives of Accounting: Hits, misses and ways 
Evidenciação das Ações Diante das Mudanças Climáticas nos Relatórios das Empresas Participantes do Carbon Disclosure Project (CDP) Brasil

forward. Critical Perspectives on Accounting, 43, 65-87. DOI: https://doi.org/10.1016/j.cpa.2016.06.005

Dias Filho, J. M. (2013). A Pesquisa Qualitativa sob a Perspectiva da Teoria da Legitimidade: uma alternativa para explicar e predizer políticas de evidenciação contábil. Interface, v. 9, n. 1, p. 72-86.

Doná, A. L., Marques, K. C. M., Moribe, A. M., \& Junior, J. B. H. (2015). Fatores determinantes do conteúdo divulgado no relatório de administração de empresas brasileiras. Revista Universo Contábil, 11(4), 82-106. DOI: $10.4270 /$ ruc. 2015433

Dwyer, R., Lamond, D., Prado-Lorenzo, J. M., Rodríguez-Domínguez, L., GallegoÁlvarez, I., \& García-Sánchez, I. M. (2009). Factors influencing the disclosure of greenhouse gas emissions in companies world-wide. Management Decision. DOI: https://doi.org/10.1108/00251740910978340

Garcia, S., Cintra, Y. C., de Souza Ribeiro, M., \& Dibbern, B. R. S. (2015). Qualidade da divulgação socioambiental: um estudo sobre a acurácia das informações contábeis nos relatórios de sustentabilidade. Revista Contemporânea de Contabilidade, 12(25), 67-94. DOl: http://dx.doi.org/10.5007/2175$8069.2015 \mathrm{v} 12 \mathrm{n} 25 \mathrm{p} 95$

Engau, C., \& Hoffmann, V. H. (2011). Strategizing in an unpredictable climate: exploring corporate strategies to cope with regulatory uncertainty. Long Range Planning, 44(1), 42-63. DOI: https://doi.org/10.1016/j.Irp.2010.11.003

Eugenio, T. P. (2010). Avanços na divulgação de informação social e ambiental pelas empresas e a teoria da legitimidade. Revista Universo Contábil, 6(1), 102118. DOl: http://dx.doi.org/10.4270/ruc.20106

Eugénio, T. P., Lourenco, I. C., \& Morais, A. I. (2013). Sustainability strategies of the company TimorL: extending the applicability of legitimacy theory. Management of Environmental Quality: An International Journal. v. 24, n. 5, p. 570-582. DOl: https://doi.org/10.1108/MEQ-03-2011-0017

Faria, J. A., Andrade, J. C. S., \& da Silva Gomes, S. M. (2018A). Fatores Determinantes da Evidenciação das Mudanças Climáticas nas Empresas Brasileiras Participantes do Carbon Disclosure Project [CDP]. Revista de Gestão Ambiental e Sustentabilidade, 7(1), 162-184.

Faria, J. A., Andrade, J. C. S., \& da Silva Gomes, S. M. (2018B). The determinants mostly disclosed by companies that are members of the Carbon Disclosure Project. Mitigation and Adaptation Strategies for Global Change, 23(7), 9951018. DOI: https://doi.org/10.1007/s1 1027-018-9785-0

Farias, K. T. R. (2009). A relação entre divulgação ambiental, desempenho ambiental e desempenho econômico nas empresas brasileiras de capital aberto: uma pesquisa utilizando equações simultâneas (Doctoral dissertation, 
Universidade de São Paulo). Faculdade de Economia, Administração e Contabilidade. Universidade de São Paulo - Ribeirão Preto.

Farias, L. D. G. Q., Andrade, J. C. S., \& Gomes, S. M. S. (2017). Estratégias de legitimidade de Suchman evidenciadas pelas empresas brasileiras destinatárias do pedido do Carbon Disclosure Project. Revista de Administração da Universidade Federal de Santa Maria, 10(5), 854-869.

Fernandes, S. M. (2012). Nível do disclosure ambiental das empresas brasileiras listadas na BM\&FBovespa: uma análise do período de 2006 a 2010. Revista de Gestão Social e Ambiental, 6(2), 106-120.

Field, A. (2009). Descobrindo a Estatística Usando o SPSS-5. $2^{a}$ edição. Penso Editora.

Gallego-Álvarez, I., Lozano, M. B., \& Rodríguez-Rosa, M. (2018). An analysis of the environmental information in international companies according to the new GRI standards. Journal of cleaner production, 182, 57-66. DOI: https://doi.org/10.1016/j.jclepro.2018.01.240

GRI, (2017). www.globalreporting.org. Global Reporting Initiative, Amsterdam.

Guia Nvivo. (2017) Manual Nvivo versão 11.4. QSR International. Disponível em: http://www.qsrinternational.com/nvivo-portuguese Acesso em: 21 de março de 2017.

Guia, L. D., Junior, C. B. M., Serrano, A. L. M., \& Franco, V. R. (2017). O Impacto de Disclosure sobre o Desempenho das Empresas Brasileiras Listadas na NYSE. Revista Reuna, 22(3), 74-91.

Hendriksen, E. S., \& Van Breda, M. F. (1999). Teoria da contabilidade; tradução de Antonio Zoratto Sanvicente. São Paulo: Atlas, 277-297.

Hengst, I. A., Jarzabkowski, P., Hoegl, M., \& Muethel, M. (2020). Toward a process theory of making sustainability strategies legitimate in action. Academy of Management Journal, 63(1), 246-271. DOl: https://doi.org/10.5465/amj.2016.0960

Hoffman, A. J., \& Woody, J. G. (2008). Climate change: what's your business strategy?. Harvard Business Press, Cambridge, MA.

latridis, G. E. (2013). Environmental disclosure quality: Evidence on environmental performance, corporate governance and value relevance. Emerging Markets Review, 14, 55-75. DOI: https://doi.org/10.1016/j.ememar.2012.11.003

Ihlen, $\varnothing ., \&$ Roper, J. (2014). Corporate reports on sustainability and sustainable development:'We have arrived'. Sustainable development, 22(1), 42-51. DOI: https://doi.org/10.1002/sd.524 
Evidenciação das Ações Diante das Mudanças Climáticas nos Relatórios das Empresas Participantes do Carbon Disclosure Project (CDP) Brasil

Kos, S. R., Espejo, M. M. D. S. B., \& Raifur, L. (2014). O conteúdo informacional do Relatório da Administração e o desempenho das empresas brasileiras do Ibovespa. Revista Universo Contábil, 10(2), 43-62. DOI: https://doi.org/10.4270/ruc.2014211

Lee, S. Y., Park, Y. S., \& Klassen, R. D. (2015). Market responses to firms' voluntary climate change information disclosure and carbon communication. Corporate Social Responsibility and Environmental Management, 22(1), 1-12. DOI: https://doi.org/10.1002/csr.1321

Linehan, C., Solicitors, W. F., House, F., \& Place, W. (2010). Financial and corporate disclosure of climate change risk- its role and recent developments. Environmental Law \& Management, 22(2), 57-71.

Lopes, A. C., De Luca, M. M. M., Góis, A. D., \& de Vasconcelos, A. C. (2017). Disclosure socioambiental, reputação corporativa e criação de valor nas empresas listadas na bm\&fbovespa. Revista Ambiente Contábil, 9(1), 364-382.

Macêdo, F. F. R. R., de Moura, G. D., Gollo, V., \& Klann, R. C. (2014). Evidenciação ambiental voluntária de companhias listadas no índice carbono eficiente da BM\&FBovespa. Race: revista de administração, contabilidade e economia, $13(1), 329-352$

Machado, D. P., \& Ott, E. (2015). Estratégias de legitimação social empregadas na evidenciação ambiental: Um estudo a luz da Teoria da legitimidade. Revista Universo Contábil, 11(1), 136-156. DOI: https://doi.org/10.4270/RUC.2015107

Mousa, G., \& Hassan, N. T. (2015). Legitimacy theory and environmental practices: Short notes. International Journal of Business and Statistical Analysis, 2(01), p. 41-53.

Murcia, F. D. R., Rover, S., Lima, I., Fávero, L. P., \& Lima, G. (2009). 'Disclosure Verde'nas demonstrações contábeis: características da informação ambiental e possíveis explicações para a divulgação voluntária. Journal of Accounting, Management and Governance, 11(1-2).

O'donovan, G. (2002). Environmental disclosures in the annual report. Accounting, Auditing \& Accountability Journal, v. 15, n. 3, p. 344-371. DOl: https://doi.org/10.1108/09513570210435870

Pereira, A. G., Bruni, A. L., \& Dias Filho, J. (2010). Legitimidade Corporativa EM Empresas Pertencentes a Indústrias Ambientalmente Sensíveis: Um Estudo Empírico com Empresas que Negociam Ações na Bovespa (Corporate Legitimacy in Companies Belonging to Environmentally Sensitive Industries: An Empirical Study with Companies that Trade Stocks on the Bovespa). Sociedade, Contabilidade e Gestão, Rio de Janeiro, 5(2).

Pires, C. B., \& da Silva Silveira, F. C. (2008). A evolução da evidenciação das informações ambientais de empresas do setor de celulose e papel: uma 
análise de conteúdo das notas explicativas e relatórios de administração. ConTexto, 8(13).

Reid, E. M., \& Toffel, M. W. (2009). Responding to public and private politics: Corporate disclosure of climate change strategies. Strategic Management Journal, 30(11), 1157-1178. DOl: https://doi.org/10.1002/smj.796

Ribeiro, V. P. L., Guzmán, C. A., da Silva Monteiro, S. M., \& Guzmán, B. A. (2012). Determining factors of environmental management practices in Portuguese local entities. Management of Environmental Quality: An International Journal. DOI: https://doi.org/10.1108/14777831211255079

Rossoni, L. (2016). O que é legitimidade organizacional?. Organizações \& Sociedade, 23(76), 110-129. DOI: https://doi.org/10.1590/1984-9230766

Rover, S., Tomazzia, E. C., Murcia, F. D. R., \& Borba, J. A. (2012). Explicações para a divulgação voluntária ambiental no Brasil utilizando a análise de regressão em painel. Revista de Administração, 47(2), 217-230. DOl: https://doi.org/10.5700/rausp 1035

Silva, M. N. D., Lima, J. A. S. D. O., Freitas, M. A. L. D., \& Lagioia, U. C. T. (2015). Determinantes do disclosure ambiental nos relatórios de empresas listadas na Bovespa. Revista Ambiente Contábil-Universidade Federal do Rio Grande do Norte-ISSN 2176-9036, 7(2), 1-15.

Silva, M. N., Rodrigues, R. N., \& Lagioia, U. C. T. (2019). É financeiramente viável ser verde? A relação entre as práticas de divulgação e a performance financeira de empresas brasileiras de alto impacto ambiental. Cuadernos de Contabilidad, 20(49), 9. DOI: https://doi.org/10.1 11 44/Javeriana.cc20-49.ffgr

Sprengel, D. C., \& Busch, T. (2011). Stakeholder engagement and environmental strategy-the case of climate change. Business Strategy and the Environment, 20(6), 351-364. DOl: https://doi.org/10.1002/bse.684

Suchman, M. C. (1995). Managing legitimacy: Strategic and institutional approaches. Academy of management review, 20(3), 571-610. DOI: https://doi.org/10.5465/amr.1995.9508080331

Sullivan, R., \& Gouldson, A. (2012). Does voluntary carbon reporting meet investors' needs?. Journal of Cleaner Production, 36, 60-67. DOI: https://doi.org/10.1016/j.jclepro.2012.02.020

Zhang, Y. J., \& Liu, J. Y. (2020). Overview of research on carbon information disclosure. Frontiers of Engineering Management, 1-16. DOl: https://doi.org/10.1007/s42524-019-0089-1 


\section{CONTRIBUIÇÕES DOS AUTORES}

\begin{tabular}{|l|c|c|c|}
\hline \multicolumn{1}{|c|}{ Contribuição } & $\begin{array}{c}\text { Juliano } \\
\text { Almeida de } \\
\text { Faria }\end{array}$ & $\begin{array}{c}\text { José Célio } \\
\text { Silveira } \\
\text { Andrade }\end{array}$ & $\begin{array}{c}\text { Sônia Maria } \\
\text { da Silva } \\
\text { Gomes }\end{array}$ \\
\hline $\begin{array}{l}\text { 1. Idealização e concepção do assunto e } \\
\text { tema da pesquisa }\end{array}$ & $\checkmark$ & $\checkmark$ & $\checkmark$ \\
\hline 2. Definição do problema de pesquisa & $\checkmark$ & $\checkmark$ & $\checkmark$ \\
\hline 3. Desenvolvimento da Plataforma Teórica & $\checkmark$ & & $\checkmark$ \\
\hline $\begin{array}{l}\text { 4. Delineamento da abordagem } \\
\text { metodológica da pesquisa }\end{array}$ & $\checkmark$ & $\checkmark$ & $\checkmark$ \\
\hline 5. Coleta de dados & $\checkmark$ & & $\checkmark$ \\
\hline $\begin{array}{l}\text { 6. Análises e interpretações dos dados } \\
\text { coletados }\end{array}$ & $\checkmark$ & $\checkmark$ & $\checkmark$ \\
\hline 7. Conclusões da pesquisa & $\checkmark$ & $\checkmark$ & \\
\hline 8. Revisão crítica do manuscrito & & & $\checkmark$ \\
\hline $\begin{array}{l}\text { 9. Redação final do manuscrito, conforme } \\
\text { as normas estabelecidas pela Revista. }\end{array}$ & $\checkmark$ & $\checkmark$ & \\
\hline 10. Orientação & & & \\
\hline
\end{tabular}

